\title{
LA ENSEÑANZA DE LOS EMIGRANTES. ENTRE LA DEFENSA DE LA IDENTIDAD ESPAÑOLA Y LA POLÍTICA DE ASIMILACIÓN FRANCESA*
}

\author{
por \\ LORENZO DELGADO GóMEZ-ESCALONILLA \\ Instituto de Historia (CSIC)
}

RESUMEN: Durante buena parte del siglo XX, la enseñanza de los emigrantes españoles en Francia ha constituido un motivo de fricción en las relaciones bilaterales. Las autoridades españolas deseaban preservar las señas de identidad nacionales y culturales de esa población, mientras que sus bomólogos franceses trataban de favorecer su integración y posterior asimilación en la sociedad de acogida. Aqui se analiza la evolución de ese contencioso desde sus compases iniciales en las primeras décadas del siglo basta el final de la dictadura franquista. Con ello, se pretende examinar el desarrollo y aplicación, por parte del gobierno español, de una política cultural y educativa dirigida a la emigración en Francia, junto a las resistencias que plantearon a esa labor los sucesivos gobiernos franceses. A la actuación de esos dos protagonistas se unió la propia acción de los emigrantes. Su movilización desde los años sesenta fue esencial para lograr que el Estado español venciera su anterior indolencia y articulara una red docente que garantizara, al menos en parte, la posibilidad de una enseñanza bilingüe para sus bijos.

Palabras Clave: Relaciones España-Francia. Política exterior. Emigración. Enseñanza. Identidad. Asimilación.

ABSTRACT: For a good part of the twentieth century, the teaching of Spanish emigrants in France bas been a source of friction in bilateral relations. The Spanish authorities wished to preserve the ballmarks of national and cultural identity in this population, while their French counterparts attempted to promote their integration and subsequent assimilation into the host society. This article analyses the evolution of this contentious issue from its beginnings in the first decades of the century to the end of the Franco dictatorship. It

* Abreviaturas de archivos empleadas: AD: Archives Diplomatiques-París; AGA: Archivo General de la Administración-Alcalá de Henares; AMAE: Archivo del Ministerio de Asuntos Exteriores-Madrid. 


\begin{abstract}
attempts to examine the development and application of the cultural and educational policy relating to emigration that was adopted by the Spanish government, along with the resistance expressed by successive French governments. The actions of these protagonists were coupled with the action of the emigrants themselves. Their mobilization from the 1960s onwards was essential in ensuring that the Spanish state overcome its previous indolence and articulate an educational network that would guarantee, at least to some degree, the possibility of a bilingual education for their children.
\end{abstract}

KEY WORDS: Relations between Spain and France. Foreign policy. Emigration. Education. National identity. Assimilation.

«Cuando los padres llegaron a Francia, llegaron a hacer un poquito de dinero y marchar; los hijos vinieron, crecieron, empezaron la escuela. Los padres nunca se han podido preocupar de poderlos seguir en la escuela, porque no sabían hablar el francés, porque desconocían totalmente muchas leyes, y ha sido siempre el hijo el que ha tenido que hacerlo todo por los padres. Llega el momento en que los chicos ya son grandes, no saben lo que quieren, los padres no saben orientarles, a muchos de ellos les cuesta mucho trabajo hasta hablar el español, los padres se van a trabajar [...] ¿que hacen los chicos en la calle mientras el padre y la madre se están matando a trabajar para el día de mañana, si llega, marchar a España? [...] tes"...» ${ }^{1}$.

Aquí todo el mundo viene y dice: "prometemos clases para los emigran-

Los estudios sobre la emigración española a Francia en el siglo XX han indagado en sus características demográficas, sus efectos económicos o las dificultades para el retorno de los emigrantes. Bastante menor ha sido la atención prestada a los fenómenos de integración y asimilación de ese colectivo ${ }^{2}$, a las medidas tomadas al respecto por los gobiernos francés y español, o a las respuestas de los emigrantes ante ellas. Sin duda una de las claves de ese proceso se encuentra en el terreno cultural y educativo, en las iniciativas desplegadas para favorecer o impedir su identificación con las pautas y valores del país de acogida.

Una investigación realizada hace unos años sobre los españoles asentados en París destacaba que su integración se producía de manera casi imperceptible, eran una emigración invisible. Pero, al mismo tiempo, ponía de relieve su resistencia a la asimilación. Ese colectivo mostraba una actitud decidida en la preservación de su identidad nacional y cultural. En parte era una manifestación defensiva frente al sentimiento de superioridad que les transmitían los ciudadanos franceses, que los aceptaban sin conflictos pero los consideraban una clase de trabajadores subordinados. También contribuía a esa conducta la

1 «Entrevista a la Directora del Centro de Formación Profesional», recogida en PARRA LUNA, Francisco: La emigración española en Francia 1962-1977, Madrid, 1981, pp. 194 y 198.

2 Una definición del significado de ambos términos ajustada a nuestro campo de reflexión en NOIRIEL, Gérard: Population, immigration et identité nationale en France XIX $X^{e}-X X^{e}$ siècle, Paris, 1992, pp. 86-87.

Hispania, LXII/2, núm. 211 (2002) $521-560$ 
expectativa del retorno a su país de origen, aunque fuese una opción a medio o largo plazo. Por último, tras la oleada migratoria de los años 50-60, la colonia de emigrantes había incrementado su dependencia respecto al Estado español, siendo este país el que disponía de la red mas amplia y diversificada de atención a sus emigrantes en Francia ${ }^{3}$.

Alguna de las afirmaciones anteriores parece contradecir la extendida opinión de que el Estado español, sobre todo durante la dictadura franquista, apenas se ocupó de sus emigrantes en el extranjero. Asimismo, se adjudica a la emigración en Francia una cierta impermeabilidad frente a la política de asimilación francesa, junto a una voluntad de mantener los lazos culturales con su país natal. En las páginas que siguen nos acercaremos a esa problemática, tomando como hilo argumental la enseñanza de los emigrantes españoles en Francia ${ }^{4}$.

\section{ORÍGENES DEL CONTENCIOSO ESCOLAR}

La emigración española a Francia y sus territorios norteafricanos venía desarrollándose desde el siglo XIX, aunque fue en las primeras décadas del siglo XX cuando adquirió mayor intensidad. La población española en suelo francés pasó de 80.425 personas en 1901 a 254.980 en 1921, en Argelia se contabilizaban otras 144.328 en esta última fecha. El crecimiento continuó en los años siguientes en el territorio metropolitano, con un moderado descenso de la colonia instalada en Argelia. En 1931 las cifras eran de 351.864 y 109.821 personas, respectivamente, cantidad que después experimentó una sensible disminución debida a la crisis económica, las naturalizaciones y los retornos favorecidos por el advenimiento de la II República española. Entre sus miembros predominaba una mano de obra de escasa cualificación y con elevados índices de analfabetismos.

Las consecuencias del fenómeno migratorio eran contempladas de forma dispar por los gobiernos de España y Francia. Para las autoridades españolas la salida de emigrantes suponía un hecho inevitable, pero no irreversible. El establecimiento de trabajadores españoles en Francia no tenía porqué significar la pérdida de sus raíces nacionales. Sus homólogos franceses, por contra, deseaban

3 TABOADA LEONETt, Isabelle et GuILlon, Michèle: Les inmigrés des beaux quartiers. La communauté espagnole dans le $16^{e}$ arrondissement de Paris, Paris, 1987.

4 Ya hace unos años, trazamos una panorámica de la cuestión durante la primera mitad del siglo XX. Aquí se retomarán algunas de aquellas reflexiones, a partir de las cuales analizaremos la evolución en esta materia para el período posterior. Vid. DeLGado, Lorenzo y NiÑo, Antonio: «Emigración, enseñanza y nacionalidad en las relaciones hispano-francesas», Historia Contemporánea, 10 (1993), pp. 51-101. №. monográfico dedicado al tema "España y Francia, en la paz y en la guerra: 1914-1945".

5 RuBIO, Javier: La emigración española a Francia, Barcelona, 1974, pp. 49 y ss. 
que el asentamiento de esa población en su territorio fuera acompañado de una progresiva asimilación a la cultura del país de acogida.

La colonia española no disponía de instituciones escolares propias para paliar su precaria formación. El único medio de escolarización para los emigrantes o sus hijos era el sistema francés de enseñanza pública. El Estado español reaccionó ante tal situación, bien es cierto que con retraso y escasa efectividad. En la década de los años veinte se planteó erigir una mínima estructura educativa que se ocupase de las necesidades de la población adulta e infantil, al tiempo que impedía que se rompieran los vínculos con su país de origen. Esa intervención chocaba con las pretensiones de las autoridades francesas, empeñadas en una política de asimilación de los emigrantes. De ahí su oposición sistemática a la creación de escuelas extranjeras. La diferencia de criterios e intereses entre ambos países iba a dar lugar a un contencioso bilateral que se prolongaría durante casi todo el siglo $\mathrm{XX}$.

A finales de 1921, poco después de su constitución, la Oficina de Relaciones Culturales del Ministerio de Estado propuso la creación urgente de escuelas españolas en Toulouse, Burdeos y Orán, núcleos de fuerte implantación de población española $a^{6}$ El centro de Toulouse debía ser el pionero, ya que disponía de un local cedido por la municipalidad y de un maestro nombrado para hacerse cargo de la escuela. Pero sus promotores no se pusieron de acuerdo sobre la acción educativa a desarrollar. El cónsul español en la ciudad proponía una enseñanza limitada a la lengua, literatura, geografía e historia de España; materias impartidas en horas suplementarias tras la jornada escolar en los centros franceses. La Oficina de Relaciones Culturales defendía la creación de escuelas autónomas e independientes, como lo eran las francesas en España. El Estado español, en cualquier caso, se mostraba renuente a traducir las buenas intenciones en dotaciones presupuestarias. La iniciativa se fue al traste.

Unos años más tarde se retomó la cuestión. Esta vez los protagonistas fueron los emigrantes instalados en Bayona. La colonia española organizaba desde 1920 unos cursos gratuitos, que se proyectó ampliar con una escuela para la población infantil. En octubre de 1924 la escuela comenzó su labor, respaldada por fondos recaudados por la colonia y por una subvención anual del Ministerio de Estado español. Sin embargo, antes de acabar el curso, un inspector de enseñanza francés exigió la autorización expresa del Consejo Superior de Instrucción Pública para permitir su funcionamiento. A partir de entonces se hizo preciso recurrir a la negociación diplomática para contar con centros escolares en Francia.

La legislación española era muy liberal con las numerosas escuelas francesas establecidas en su territorio, que gozaban de una considerable autonomía. Esas facilidades no se plasmaron en una reciprocidad de trato para las escuelas espa-

6 «Necesidad de plantearse y realizar un programa de política cultural fuera de España», s.f. AMAE, R-1380/26.

Hispania, LXII/2, núm. 211 (2002) 521-560 
ñolas en suelo francés. Para las autoridades del país vecino, la apertura de escuelas extranjeras promovía la conservación de las culturas de origen y, por extensión, trataba de frenar la asimilación de los emigrantes. Esos propósitos entraban en colisión con una política que buscaba utilizar el aporte migratorio como medio de paliar la crisis demográfica nacional. La legislación francesa se mostraba muy restrictiva: prohibía la apertura de escuelas extranjeras dirigidas por profesores que no tuvieran los títulos de maestros franceses. La escuela de la III República era portadora de los valores constitutivos de la nación, y sancionaba el cuasi monopolio de los enseñantes franceses? ${ }^{7}$. A esas complicaciones se añadía una dimensión política. El mayor contingente de emigrantes en Francia procedía de Italia y Polonia, cuyos gobiernos tenían pretensiones idénticas a las españolas, pero con unas repercusiones mucho más delicadas. Se corría el peligro de la organización de minorías nacionales de otros países en suelo francés, sin descartar que en el futuro esas mismas reivindicaciones se plantearan en las zonas limitrofes con Alemania.

Las autoridades francesas adoptaron una posición dilatoria, sin dar una respuesta negativa. Para salvar los obstáculos legales a la reapertura de la escuela, los responsables municipales y docentes de Bayona sugirieron poner a su frente a maestros franceses. La diplomacia española no aceptó esa solución, que consideraba «una dejación de nuestros derechos, basados en un principio de equidad, para abrir escuelas españolas en Francia» ${ }^{8}$. Ante la insistencia española, una contrapropuesta formulada en 1926 proponía la realización de cursos de español en las escuelas públicas francesas, fuera del horario lectivo y bajo la autoridad de directores franceses ${ }^{9}$. La Sección de Relaciones Culturales, sucesora de la Oficina, se pronunciaba por la estricta aplicación del principio de reciprocidad. Si las autoridades francesas continuaban negándose, debían tomarse medidas contra sus establecimientos de enseñanza en España. El Ministerio de Instrucción Pública asumía esa postura, pero tanto la Sección de Política General como el embajador en París preferían emplear la persuasión. Las veladas amenazas españolas no inquietaban a los representantes franceses. Eran conscientes de que sus centros ni siquiera cumplían los requisitos fijados por la legislación española, pero dada la penuria del sistema de enseñanza de este país sus dirigentes se lo pensarían dos veces antes de tomar represalias contra su red docente ${ }^{10}$.

7 SCHOR, Ralph: Histoire de limmigration en France de la fin du XIX siècle à nos jours, Paris, 1996, p. 96.

8 «Nota de la Oficina de Relaciones Internacionales», 14-IV-1926. AMAE, R-2527/75.

9 La oferta sería reiterada años más tarde, en respuesta a las demandas españolas. «Nota del Ministro francés de Asuntos Exteriores al Embajador español en Francia», 4-XII-1929. AMAE, R$2575 / 75$.

10 «Dépêche de l'Ambassadeur français en Espagne au Ministre des Affaires Etrangères», 30XI-1925; «Note sur la situation legale des Ecoles Françaises en Espagne», s.f. AD, Europe 19181940, Espagne, vol. 122.

Hispania, LXII/2, núm. 211 (2002) 521-560 
Cuatro años más tarde las cosas seguían igual. Los franceses no habían hecho ninguna concesión, sin que ello afectara al desenvolvimiento de sus centros. La escuela de Bayona permanecía cerrada y paralizadas el resto de las que se proyectaron. Las gestiones paralelas para la creación de escuelas en Argelia y el Marruecos francés corrieron idéntica fortuna. No topaban con una negativa de plano francesa, sino con la táctica de dar largas para que el asunto languideciera entre la abulia y la falta de perseverancia de la administración española. Después de todo, no era un problema que estuviera entre las prioridades políticas de las relaciones bilaterales.

Los emigrantes continuaban sin escuelas españolas. Su única alternativa seguía siendo la escolarización en centros franceses. Sin capacidad de elección, por lo tanto, la escuela era percibida como un instrumento de promoción social en el país de acogida, sobre todo para sus hijos. Allí aprenderían la lengua y la cultura francesas y obtendrían el certificado de estudios básicos. Sus posibilidades de formación solían agotarse en ese nivel, ya que no disponían de las mismas oportunidades que sus compañeros franceses. Pero con ello podían superar la categoría inferior de peones que ocupaban sus padres, para aspirar a puestos de obreros especializados o empleados. La escuela favorecía la integración al crear expectativas de lograr una mejora de la situación socio-profesional. Simultáneamente, las experiencias y las vivencias cotidianas favorecían una homogeneización de las pautas de conducta. Una de las secuelas de ese proceso era el progresivo distanciamiento de su cultura y su país de origen. En 1930 se contabilizaban unas 140.000 personas, españoles o hijos de éstos, que habían adquirido la nacionalidad francesa. Es decir, más de una cuarta parte de los emigrantes o sus descendientes habían sido asimilados por el país receptor ${ }^{11}$.

\section{LOS FRUTOS DE LA POLÍTICA POSIBILISTA DE LA II REPÚBLICA}

Mientras que los anteriores gobiernos de la monarquía española se atrincheraron en el principio de reciprocidad, sin poner los medios para llevarlo a la práctica, los nuevos dirigentes republicanos fueron más modestos, más prácticos y más sensibles a las necesidades culturales de la emigración. En septiembre de 1931, el Ministerio de Instrucción Pública establecía la normativa de provisión de escuelas españolas en el extranjero. Los candidatos debían ser maestros de escuela nacional y aprobar un concurso-examen. La Junta de Relaciones Culturales del Ministerio de Estado se encargaría de determinar sus competencias y supervisar su labor ${ }^{12}$. En noviembre de ese mismo año, se comunicó al gobierno francés la aceptación de su anterior propuesta: la realización de cursos

\footnotetext{
11 SCHOR, Ralph: Histoire de limmigration..., pp. 100-102; RUBIO, Javier: La emigración española..., pp. 142-143.

12 «Decreto de 29-IX-1931». Gaceta de Madrid, 6-X-1931.
} 
en colegios públicos franceses, impartidos por maestros españoles en horario extraescolar, dedicados a la enseñanza de la lengua, la literatura y la historia de España, y con prohibición expresa de crear escuelas españolas independientes. En febrero de 1932, el gobierno francés transmitió su acuerdo formal.

El contencioso escolar se zanjó, momentáneamente, con la misma solución adoptada para los núcleos de población italiana y polaca instalados en Francia. La opción tomada permitía al fin desplegar una acción cultural hacia los emigrantes. Además, resultaba factible su aplicación inmediata pues no implicaba una gran inversión presupuestaria. La primera promoción de maestros en el extranjero fue nombrada en noviembre de 1932. Seis de ellos eran destinados a ciudades francesas: Aubervilliers, Toulouse, Burdeos, Bayona, Sète y Perpignan. El horizonte, empero, aún no estaba despejado para los maestros españoles.

Entre fines de 1932 y principios de 1933 se incorporaron a sus lugares de destino, pero tuvieron que afrontar las trabas que ponían los inspectores de enseñanza locales y los directores de escuelas para permitir el ejercicio de su labor. En unos casos se escudaban en la falta de instrucciones al respecto, en otros en dificultades administrativas. Una nueva intervención de la embajada española en París ante los ministerios franceses implicados permitió solventar esos obstáculos. La atmósfera de colaboración que existía entonces entre las dos repúblicas vecinas, plasmada también en el mes de noviembre en la aprobación de un Tratado de Trabajo y Asistencia Social para los emigrantes, facilitó las $\cos ^{13}{ }^{13}$. Entrado el año 1933, los maestros españoles pudieron comenzar sus actividades.

Ese mismo año, la Junta de Relaciones Culturales creó otras 15 clases españolas. Cinco de ellas en Francia: Paris, Raismes, Marsella, Lyon y Pau. Las otras diez en Argelia: Orán (4), Sidi-Bel-Abbés (2), Argel (2), Mostaganem y El Biar. Estas últimas suscitaron de nuevo la resistencia francesa. Según su interpretación, la autorización para las clases de español se limitaba al territorio metropolitano. El gobierno español hubo de formular una nueva petición extensiva a Argelia. Los franceses recurrieron una vez mas a la táctica dilatoria de no ofrecer contestación. Sin embargo, ahora existía una mayor sensibilidad social ante esas cuestiones, que se plamó en una interpelación parlamentaria, presentada por diputados socialistas, para que el gobierno actuase y pusiera coto a la situación de abandono que sufría la colonia española en Orán. La prensa se hizo eco del asunto y la diplomacia española se movilizó para forzar un compromiso, que llegó finalmente en agosto de 1933.

La dotación inicial de maestros era exigua para el número de emigrantes. La Junta de Relaciones Culturales contaba con recursos limitados. El objetivo, a corto plazo, era acometer la empresa con modestia pero con garantías: una adecuada selección de los docentes, un seguimiento de su labor, una buena orienta-

13 Miralles, Ricardo y AUbert, Paul: «Relaciones históricas entre España y Francia», en Del reencuentro a la convergencia. Historia de las relaciones bilaterales hispano-francesas, Madrid, 1994, pp. 67 y ss.

Hispania, LXII/2, núm. 211 (2002) 521-560 
ción pedagógica, y una actuación paralela para ganar la colaboración del conjunto de la colonia española. La campaña de promoción educativa emprendida en el interior del país no podía olvidarse de sus ciudadanos en el extranjero.

El trabajo de los maestros abarcaba frecuentemente varias escuelas. Se impartían dos horas diarias de clase al término del horario escolar, lo que implicaba un esfuerzo suplementario para los niños. Allí donde resultaba posible, en locales cedidos por los consulados o por los centros sociales españoles, los maestros organizaban otras dos horas diarias de clases para adultos, en horario nocturno. La enseñanza del castellano concentraba buena parte de su labor, pues los niños tenían un conocimiento deficiente de la lengua, apenas sabían escribirla y sólo la usaban para comunicarse con sus padres. Ese desconocimiento era más agudo entre los emigrantes de origen valenciano o catalán, asentados principalmente en Argelia. La geografía y la historia españolas eran las otras materias de enseñanza, dedicándose sesiones a conmemorar fechas señaladas como el 14 de abril o el 12 de octubre. En aquellos actos los maestros se convertían en propagandistas de su país y de la República, glosando el progreso político, social y cultural a que aspiraba el nuevo régimen ${ }^{14}$.

En 1934 se enviaron instrucciones a todos los docentes para homogeneizar su actuación. También empezó a suministrarse material de apoyo: gramófonos, aparatos de proyección, películas educativas y diapositivas, estableciéndose una filmoteca central en el Colegio de España de la Ciudad Universitaria de París. Se pretendía aplicar una pedagogía activa y directa. La enseñanza se apoyaba con la lectura y comentario de informaciones de actualidad, la confección de periódicos escolares, las audiciones de música, la proyeccción de películas, el reparto de libros, los paseos y excursiones por el campo, etc. Los maestros tenían además a su cargo bibliotecas circulantes. Durante las vacaciones estivales, se organizaron viajes a España para los hijos de los emigrantes, aproximándoles así a sus tierras y sus ciudades, al trato con sus compatriotas, estimulando en ellos el sentimiento de la nacionalidad ${ }^{15}$.

Los maestros simultaneaban la actividad docente con la labor social. Tenían que visitar a las familias, pues necesitaban una autorización expresa de los padres para que sus hijos asistieran a las clases de español. Asimismo, debían entrar en contacto con las organizaciones expañolas de su demarcación, para animarles a formar, junto con los padres de los alumnos, Sociedades de Amigos de las Clases que respaldaran la obra de difusión cultural. En localidades donde las condiciones económicas de las familias eran muy precarias, se procuró poner en marcha cantinas escolares. En suma, los maestros actuaban como una suerte de misioneros que la república enviaba al extranjero para rescatar del abandono a sus ciudadanos emigrados.

\footnotetext{
14 Los detalles sobre la labor de los maestros están recogidos en las memorias que remitían trimestralmente a la Junta. Un resumen en Junta de Relaciones Culturales. Memoria correspondiente a los años 1931 a 1933, Madrid, 1934, pp. 11-20.

15 Junta de Relaciones Culturales. Memoria correspondiente al año 1934, Madrid, 1935, pp. 9-31. 
Aunque el trabajo de los docentes se vió a veces perturbado por las desavenencias políticas o personales que existían en el seno de las colonias de emigrantes, por lo general su intervención contribuyó a mitigar esas tensiones. Los cónsules españoles destacaban su capacidad y su espíritu patriótico, considerándolos unos valiosos colaboradores. También lo resaltaba el ilustre pedagogo y Secretario de la Junta, Lorenzo Luzuriaga, tras uno de sus viajes anuales de inspección a las clases en el extranjero: "los maestros coadyuvan a la acción de dichas autoridades, sobre todo en los medios extremistas, atrayéndolos hacia los representantes de España y a las ideas nacionales» ${ }^{16}$.

El voluntarismo y el entusiasmo de los docentes no ocultaba, pese a todo, que los medios a su disposición eran insuficientes, que las clases de adultos se daban a menudo en locales inadecuados, que el rendimiento de los niños se resentía de la prolongación de sus horarios escolares, o que la situación de dependencia en que se encontraban con respecto a las escuelas francesas entorpecía su trabajo. Si la política posibilista de la II República había conseguido romper inercias de inactividad y obstruccionismo, aún quedaba mucho camino por recorrer. Por ello, no eran infrecuentes las airadas manifestaciones de algunos responsables diplomáticos contra las limitaciones impuestas por la nación vecina en el terreno escolar, especialmente en Argelia. La descompensación con las facilidades de que gozaban los centros escolares franceses en España producía una fuerte sensación de agravio ${ }^{17}$. Las repercusiones de ese malestar se dejaron sentir pocos años después, acentuadas por la francofobia de un nutrido sector de los dirigentes del bando vencedor en la guerra civil.

Durante la II República, en suma, se articuló una infraestructura docente que, pese a sus limitaciones y a los obstáculos encontrados, atendía por primera vez las necesidades educativas de la emigración. Al acabar el curso 1935-36 había 21 maestros en Francia y Argelia. El número de alumnos infantiles y adultos variaba mucho de un lugar a otro, concentrándose un mayor volumen de población escolar en Perpiñán (con 411 alumnos), Burdeos (con 289) y Toulouse (con 245). En conjunto, los maestros españoles llegaron a impartir clases a casi 2.000 alumnos en la Francia metropolitana, y a unos 350 en Argelia ${ }^{18}$. También por entonces, comenzaba a plantearse la conveniencia de crear un certificado de estudios primarios de español. La guerra civil paralizó todas esas actividades y proyectos.

\footnotetext{
16 «Informe de Luzuriaga sobre su visita de inspección a las escuelas y clases españolas en Francia», 6-VI-1935. AMAE, R-1241/14.

17 Vid. «Cónsul General de España en Orán al Secretario de la Junta de Relaciones Culturales", 4-VI-1934. AMAE, R-1241/13.

18 Los datos proceden de los informes enviados por los maestros para la memoria correspondiente a aquel año, que no llegó a publicarse, en AMAE, R-727/19.
}

Hispania, LXII/2, núm. 211 (2002) 521-560 


\section{LA OBTENCIÓN DE UN COMPROMISO DE RECIPROCIDAD}

Disponemos de escasos datos sobre la situación de los maestros durante los tres años que duró la contienda interior. Un buen número de ellos se encontraban en España al desencadenarse la sublevación, bien de vacaciones o bien a cargo de grupos de niños en viaje de estudios. La mayoría permaneció leal al gobierno republicano, que les restituyó a sus puestos hasta que problemas más acuciantes, como la atención de los niños evacuados al extranjero, hicieron que una parte de ellos fueran destinados a esa labor. En Francia sólo actuaron los docentes nombrados por las autoridades republicanas, pues el gobierno galo no reconoció al bando insurgente hasta poco antes del final del conflicto.

La victoria de las fuerzas dirigidas por el general Franco iba a tener efectos casi inmediatos sobre las relaciones culturales bilaterales. El apoyo prestado a la causa republicana por los dirigentes del país vecino, a pesar de su inconstancia y su inhibición en momentos claves, había acentuado entre los vencedores la animadversión hacia Francia. Además, se la hacía responsable, junto a Gran Bretaña, de la decadencia nacional y la frustración de sus aspiraciones exteriores.

En abril de 1939, recien terminada la guerra civil, el responsable de la propaganda franquista en Francia, Joan Estelrich, avanzaba un replanteamiento de las relaciones culturales entre ambos países. La educación de los emigrantes suponía uno de sus puntos candentes, ya que las colonias españolas sufrían «el yugo oficial de Francia, que tendía a afrancesarlas y a obligarlas a olvidar su lengua materna» ${ }^{19}$. Había que poner coto a esa política de asimilación para preservar la españolidad de los compatriotas residentes en Francia y en sus territorios norteafricanos. Para ello, debía exigirse un estatuto cultural que permitiera a España intensificar la acción cultural entre sus ciudadanos allí instalados. Poco después, los dirigentes españoles empezaron a dar muestras de una mayor determinación en esa materia.

En el mes de agosto la Embajada de Francia solicitó la autorización del Ministerio de Educación Nacional para la apertura de su red docente. Era la primera vez que esto ocurría. Hasta entonces sus instituciones se habían beneficiado de la ausencia de una normativa que controlase la enseñanza en los centros extranjeros. La legislación educativa promulgada por la España franquista terminó con esa liberalidad. En lo sucesivo, los establecimientos pertenecientes a personas o entidades extranjeras serían objeto de acuerdos especiales de reciprocidad cultural. La autorización requerida no se concedió hasta casi dos meses más tarde, a mediados de octubre, pese a la insistencia de la diplomacia francesa y a la gestión personal de su embajador, el mariscal Petain, ante el ministro de Asuntos Exteriores. Ese desfase temporal era indicativo de la actitud reticente de las autoridades españolas, que dieron a la medida un carácter provisional para ese curso escolar. Su prolongación quedó «subordinada a la

19 «Notas sobre las relaciones culturales hispano-francesas», 11-IV-1939. AMAE, R-1380/24.

Hispania, LXII/2, núm. 211 (2002) 521-560 
reciprocidad de trato que en Francia se conceda a los establecimientos de enseñanza españoles en ella establecidos» ${ }^{20}$.

Paralelamente, se pidió a los representantes diplomáticos españoles en Francia y Argelia que informaran sobre la acción cultural que podía desarrollarse para atender a la colonia española. El embajador en París se pronunció por reanudar lo antes posible las actividades docentes, con el nombramiento de nuevos maestros ${ }^{21}$. Los informes remitidos desde Argelia también demandaban el envío de maestros, pero se mostraban más críticos frente a la política de asimilación practicada por Francia, e insistían en la necesidad de asumir una postura de firmeza ${ }^{22}$.

En julio de 1940, volvió a solicitarse la preceptiva autorización para los centros escolares franceses en España. En agosto, el ministro de Educación Nacional notificaba a su homólogo de Asuntos Exteriores que las escuelas españolas de Casablanca no podían reanudar sus actividades, debido a las trabas que ponían las autoridades francesas de Rabat. Esas escuelas, fundadas durante la II República por el ministerio de Instrucción Pública, habían mantenido su labor docente incluso durante la guerra civil. Ante tal situación, se comunicó al gobierno francés que la renovación del permiso para sus centros escolares quedaba condicionada a que funcionasen "con toda normalidad las escuelas españolas de Casablanca y todas aquellas que estimemos oportuno establecer en territorio de soberanía o protectorado francés hasta igualar el número de establecimientos de enseñanza franceses en territorio español». Se habían acabado las dilaciones, o se aceptaba la reciprocidad de trato en materia escolar o la red docente francesa sería clausurada ${ }^{23}$.

El momento escogido no era casual. La exigencia de reciprocidad, y la amenaza del cierre de sus centros en caso de no obtenerse, se le planteaban a una Francia recien derrotada por las tropas alemanas. El régimen español aprovechaba la ocasión para acabar con un desequilibrio bilateral que se arrastraba desde dos décadas atrás. El Estado francés disponía de un menor margen de maniobra frente a esas demandas. El nuevo gobierno, encabezado por el mariscal Petain, aspiraba a mantener buenas relaciones con el general Franco, cuya

20 «Notes verbales de l'Ambassade de France en Espagne», 23-VIII y 12-IX-1939; «Petain a Beigbeder», 23-VIII-1939; «Autorización para que funcionen establecimientos franceses en España», 14-X-1939. AD, Europe 1944-1949, Espagne, vol. 97. AMAE, R-8586/20.

21 «Acción cultural en Francia», 16-XI-1939. AMAE, R-2467/64.

22 «Informa acerca del estado en que se encuentran las escuelas españolas», 9-VIII-1939. AMAE, R-2791/7.

23 «Note verbale», 24-VII-1940; «Sobre la apertura de las escuelas españolas de Casablanca y la autorización provisional por el presente curso de los centros franceses establecidos en España», 8VIII-1940; «Reciprocidad de trato para los establecimientos culturales españoles en Francia y territorio sometido a su protectorado y para los establecimientos culturales franceses en territorio de soberanía o protectorado de España», 25-VIII y 13-IX-1940; «Ministerio de Asuntos Exteriores a la Embajada de Francia en España», 31-VIII-1940. AMAE, R-8586/20.

Hispania, LXII/2, núm. 211 (2002) 521-560 
sintonía con las potencias fascistas era una baza que no convenía menospreciar. Las negociaciones para una posible entrada de España en la guerra estaban en su cenit. Las reivindicaciones territoriales españolas tenían su punto de mira en las colonias francesas del norte de África, como compensación por su implicación bélica. En tal tesitura, el contencioso escolar era un asunto menor. Convenía atenuar las manifestaciones más extremas del revisionismo español haciendo concesiones en asuntos menos conflictivos. Así pues, las autoridades francesas se mostraron dispuestas a acceder a los requerimientos españoles.

A finales del mes de septiembre, el embajador francés informaba a las autoridades del país vecino que su gobierno aceptaba la enseñanza de profesores españoles en las escuelas francesas, daba su autorización a la escuela española de Casablanca, y admitía que cada país pudiera mantener en el otro, «sobre las bases de la reciprocidad, el mismo número de escuelas en la Francia metropolitana y en la España metropolitana, de una parte, en el África española y el África francesa, de la otra». La declaración señalaba también que en esas escuelas se impartirían las materias de lengua, historia y geografía del país de origen. Como colofón, volvía a pedirse una "autorización definitiva» para las escuelas francesas en España. El gobierno de Franco acogió con satisfacción la respuesta, dando luz verde para que los centros escolares franceses pudieran «funcionar con toda normalidad». Poco después, las escuelas de Casablanca recibieron permiso de apertura «a título excepcional y provisional», aunque verbalmente se aclaraba que era una mera fórmula administrativa de carácter transitorio ${ }^{24}$. A pesar del acuerdo de principio alcanzado, los matices apuntados ponían de relieve la desconfianza mutua que seguía existiendo entre ambos gobiernos. Ninguno de ellos emitía una autorización definitiva de funcionamiento para los centros escolares del otro país.

En el mes de octubre, tras la entrevista de Hendaya entre Hitler y Franco, la incorporación de España a la guerra se postergó a una fecha indefinida. A partir de entonces, el gobierno español intensificó su acción sobre las colonias de emigrantes en territorio francés. Se trataba de fomentar la españolización de los compatriotas asentados en localidades del mediodía francés o en el norte de Africa, a través del mantenimiento de su lengua de origen y de la exaltación de su espíritu patriótico. Al mismo tiempo, se pretendía favorecer là implantación cultural española en la región norteafricana, como un medio de mantener las expectativas sobre esos territorios ante una futura recomposición del mapa colonial tras la victoria de las armas del Eje.

Las medidas tomadas para llevar a la práctica el compromiso de reciprocidad se fueron desplegando a lo largo de 1941. En el mes de febrero, el Ministe-

24 «L'Ambassadeur de France en Espagne au Ministre des Affaires Extérieures», 21-IX-1940; «Ministro de Asuntos Exteriores al Embajador de Francia en España», 23-IX-1940. AD, Europe, 1944-1949, Espagne, vol. 97, y AMAE, R-8586/20. «Rectificación permiso escuelas en Casablanca», 11-XI-1940. AMAE, R-8586/21.

Hispania, LXII/2, núm. 211 (2002) 521-560 
rio de Asuntos Exteriores y la Delegación Nacional de la Falange Exterior regulaban la realización de estancias en España de grupos de niños residentes en el extranjero, destinadas a estimular su formación moral y patriótica. A mediados de junio, se enviaban instrucciones a los maestros. Las clases de las escuelas españolas se adecuarían al sistema vigente en el país de acogida; las impartidas en centros escolares extranjeros comprenderían cursos de Lengua, Geografía e Historia de España. Esta última materia revestía una particular significación, al conjugarse con la difusión de «los principios y desarrollo de nuestro Movimiento Nacional». La organización pedagógica apenas difería del modelo diseñado durante el período republicano, eso sí con una carga ideológica distinta y aún más acusada. Así lo testimoniaban las «fechas señaladas» objeto de conmemoración: día de la Victoria, Alzamiento nacional, día del Caudillo, etc., junto a un buen número de efemérides religiosas. $\mathrm{Al}$ igual que en el interior del país, el adoctrinamiento político y religioso permeabilizaba el ideario educativo. Poco después, en agosto, otra disposición establecía la creación de Patronatos para el fomento de la cultura española, medida que remedaba la iniciativa republicana de las Sociedades de Amigos de las Clases ${ }^{25}$.

En los meses finales de 1941 tuvo lugar una nueva ronda de conversaciones entre funcionarios españoles y franceses sobre los problemas escolares comunes. El gobierno español quería formalizar un acuerdo que garantizase el compromiso de reciprocidad obtenido el año anterior, con un radio de acción que abarcase: la apertura sin restricciones de escuelas de primera enseñanza, institutos de enseñanza secundaria y centros de enseñanza técnica elemental; el nombramiento de maestros, lectores y catedráticos para esos establecimientos; la expedición y homologación de certificados de estudios primarios validos para ambos países; junto a la reserva para las actividades docentes en centros del otro país de un mínimo de tres clases semanales para cada grupo de alumnos, dentro del horario escolar normal. El acuerdo tendría un plazo de duración de diez años, siendo aplicable al ámbito metropolitano y a las posesiones coloniales. Esta última dimensión interesaba especialmente a los negociadores españoles, al tiempo que inquietaba a sus interlocutores del país vecirio. Las autoridades francesas optaron por tomarse un tiempo para meditar esas propuestas y exponer su punto de vista ${ }^{26}$.

25 Una exposición más detallada del contenido de las medidas comentadas en DeLGADo GóMEZ-ESCALONILLA, Lorenzo: Imperio de papel. Acción cultural y politica exterior durante el primer franquismo, Madrid, CSIC, 1992, pp. 188-190.

26 «Nota de los puntos que han de servir de base para las conversaciones con la representación diplomática de Francia a fin de llegar a un acuerdo sobre problemas culturales», 22-XI-1941; «Acta de la reunión con funcionarios de la Embajada de Francia», 2-XII-1941. AMAE, R-8586/20.

Hispania, LXII/2, núm. 211 (2002) 521-560 


\section{UN DESPLIEGUE SOBRE EL PAPEL, UNA OPORTUNIDAD PERDIDA}

Entretanto, el cuadro docente español en territorio francés se había ido restableciendo de forma paulatina. Inicialmente, se designaron 12 maestros con destino a escuelas en: París-Aubervilliers (2), Sète, Bayona, Beziers, Biarritz, Burdeos, Toulouse y Marsella, y también en Argel, Orán y Mostaganem. Al comienzo del curso 1941-1942, el Ministerio de Educación Nacional disponía la creación, con carácter definitivo, de 10 escuelas unitarias «genuinamente españolas» en poblaciones de Francia (Perpignan, Pau, Lyon, París, Marsella y Toulouse) y el norte de Africa (Mostaganem, El Biar, Orán y Argel). En agosto de 1942, se convocaron 15 plazas de maestros y 13 de maestras para escuelas ubicadas sobre todo en el norte de Africa y, en menor proporción, en Francia ${ }^{27}$. Uno de los maestros de la primera promoción republicana de docentes en el exterior, Remigio Sáez Soler, que manifestó su adhesión al bando sublevado durante la guerra civil, fue nombrado inspector de esa red escolar.

Pero tal despliegue pronto se demostró más teórico que práctico. Los maestros comenzarían su labor integrándose en escuelas francesas que contaban con una presencia suficiente de alumnos españoles. No obstante, para enseñar en dichos centros, los maestros debían cumplir con los requisitos establecidos por una circular gubernativa del 12 de julio de 1939: entrega del acta de nacimiento, título de estudios realizados, certificado del ejercicio de la profesión y programa detallado de los cursos. El cumplimiento de esos trámites retrasó el inicio de su actividad.

En cuanto a las escuelas «genuinamente españolas», en su mayor parte no existieron más allá del papel. La búsqueda de locales constituyó una dificultad añadida, pues se habían perdido buena parte de los existentes en la época republicana. En algunas localidades se alquilaron inmuebles, o se instalaron clases improvisadas en dependencias de los consulados. Las clases eran impartidas por los maestros españoles destinados en las escuelas francesas, en horario extraescolar. Lo más frecuente fue empezar por la organización de clases de adultos, que pretendían ser el embrión de las escuelas españolas. Así se procedió en Béziers, Lyon, Marsella, Pau y en el Patronato Español de Santa Teresa de Jesús en París. En Perpignan se proyectó una escuela graduada, que no llegó a convertirse en realidad. Tan sólo en Bayona y Biarritz se crearon tales escuelas, aunque su actuación fue muy modesta. Lo cierto es que, con la salvedad de las clases de París que contaron con un moderado nivel de asistencia, en el resto de los casos el número de alumnos, infantiles o adultos, fue bastante reducido -inferior casi siempre a la treintena. Los locales de las clases albergaron las bibliotecas

27 «Ordenes del Ministerio de Educación Nacional», 5-IX-1941 y 3-VIII-1942. Boletín Oficial del Estado, 17-IX-1941, y Boletín Oficial del Ministerio de Educación Nacional, 31-VIII-1942.

Hispania, LXII/2, núm. 211 (2002) 521-560 
circulantes y los Patronatos, con las miras puestas en la constitución futura de Hogares Españoles que integrasen todas esas instalaciones ${ }^{28}$.

El único centro cuya labor tuvo una cierta incidencia entre la población emigrante fue el Solar Español de Burdeos, creado en 1920. Durante la guerra civil esta institución, atendida por religiosos, fue reconocida como «el baluarte oficial de la Nueva España». Desde 1940 contó con una subvención de la Sección de Relaciones Culturales. La asistencia escolar era la más numerosa de los centros docentes españoles, con una matrícula que superaba los 400 alumnos en 1941. Se impartían clases para niños y adultos, junto a conferencias sobre «el ideario, causas, marcha y desarrollo triunfal de nuestra Santa Cruzada». En 1941 puso en marcha, en colaboración con el Auxilio Social falangista, una colonia infantil de vacaciones para los hijos de los emigrantes — situada en Prechat, a $60 \mathrm{kms}$. de Burdeos. En sus instalaciones se reunió a poco más de un centenar de niños y niñas, con un régimen análogo al practicado en España en los campamentos del Frente de Juventudes ${ }^{29}$. Otra colonia de vacaciones estivales, en este caso a cargo de la filial falangista de París, se instaló en el castillo de La Valette - a $100 \mathrm{kms}$. de París. Esa misma organización fundó un Hogar Español, con una escuela de adultos y una biblioteca circulante.

En cualquier caso, la distancia entre los decretos oficiales y la situación sobre el terreno resultaba evidente. Las autoridades francesas no facilitaban las cosas. Sus dilaciones impidieron que ninguna de las escuelas españolas proyectadas obtuviera el placet gubernamental. A esa actitud obstruccionista tampoco escaparon las clases en escuelas francesas. El Inspector español describía el procedimiento en estos términos: «el Ministerio de Instrucción Pública francés siempre dice sí, pero luego de que se oiga al Alcalde, Prefecto, Inspector de Academia y hasta los Directores de las escuelas. Cuando por tantos sitios ha de pasar un permiso nada tiene de extraño se le torpedee y hasta se restrinjan al mínimo las horas de labor» ${ }^{30}$.

Los dirigentes españoles, en contrapartida, también se aplicaron con un celo particular a la vigilancia de las escuelas francesas. A finales de 1940 la escuela de Bilbao, que era calificada como «un refugio para los elementos separatistas y de izquierdas", sufrió un cierre temporal por no satisfacer las condiciones exigidas de separación de sexos, enseñanza de la religión a todos los alumnos, y

28 El material escolar recomendado para las clases españolas comprendía Cuadernos de Ejercicios Gramaticales y Apuntes de Geografía e Historia de España, junto a libros de lectura acordes con el sesgo ideológico del régimen franquista (Así quiero ser, Simbolos de España, Glorias Imperiales o El libro de España). «Informe del Inspector luego de su visita a las poblaciones de la Francia no ocupada donde existen escuelas españolas», 17-V-1941. AMAE, R-8586/20. «Memoria del Inspector luego de su visita a los centros de enseñanza situados en Francia (Zona ocupada)», 17-XI-1941. AMAE, R-7047/17.

29 Vid. el folleto Auxilio Social en Burdeos. AGA-Secretaría General del Movimiento, caja 60.

30 «Memoria del Inspector luego de su visita a las escuelas españolas en Francia (Zona no ocupada), 8-VI-1942. AMAE, R-7047/17. 
un mínimo de seis horas semanales por curso destinadas al estudio del idioma, la geografía y la historia de España, impartidas por profesores nombrados por las autoridades españolas. Al año siguiente se prohibió la admisión de alumnos españoles en otras escuelas francesas, en tanto no se cumplieran las medidas apuntadas. Desde principios de 1942, a esos requisitos se añadió el envío obligatorio de una relación de los libros de texto y del plan de enseñanza en la clase de religión, junto a la presentación de una memoria sobre la labor desarrollada al finalizar el curso ${ }^{31}$.

Ante los constantes roces que la cuestión escolar provocaba en las relaciones bilaterales, el gobierno francés decidió aceptar la propuesta española de suscribir un acuerdo cultural que reglamentase la situación de los establecimientos de enseñanza instalados en el otro país. En abril de 1942, la embajada francesa hacía llegar un proyecto de acuerdo al Ministerio de Asuntos Exteriores, tomando como base el compromiso de reciprocidad alcanzado en septiembre de 1940. Sin embargo, los cambios en la cúpula diplomática francesa y, meses después, en la española, unidos al curso de los acontecimientos internacionales, postergaron sine die la firma de ese acuerdo cultural ${ }^{32}$. En noviembre de ese año, las tropas alemanas ocupaban la zona sur de Francia y el gobierno de Vichy perdía todo atisbo de soberanía sobre el país.

Las dificultades para el desenvolvimiento de las clases españolas continuaron hasta el final del conflicto mundial, acompañadas de protestas de la diplomacia española por los obstáculos que encontraban los maestros ${ }^{33}$. En mayo de 1943, el número de docentes que desempeñaban su labor en escuelas francesas ascendía a 14, destinados en Aubervilliers-París, Bayona, Béziers, Biarritz, Burdeos, Lyon, Marsella (3), Pau, Perpignan (2), Sète y Toulouse. La media de receptores de esas clases, según los datos que enviaban los maestros, osciló entre los 50 y los 100 alumnos, cifra superada de forma continua solamente en Marsella ${ }^{34}$.

La anhelada reciprocidad no se consumó. El funcionamiento de las clases españolas en escuelas francesas no tuvo la continuidad suficiente para cuajar entre las colectividades de emigrantes. La postura reivindicativa de las nuevas autoridades españolas había arrancado a sus homólogos franceses un compro-

31 «Inspección provincial de Primera Enseñanza de Vizcaya», 29-XI-1940; «Escuela francesa en Bilbao», 5 y 10-II-1941. AMAE, R-8586/20. «Notes verbales de l'Ambassade de France en Espagne au Ministère des Affaires Extérieures», 25-XI y 2-XII-1941; «Nota urgente del Ministerio de Asuntos Exteriores a la Embajada de Francia en España», 29-XI-1941. AMAE, R-8586/10. «Nota verbal del Ministerio de Asuntos Exteriores a la Embajada de Francia en España», 5-II-1942. AMAE, R-8586/9.

32 «Note verbale de l'Ambassade de France en Espagne au Ministère des Affaires Extérieures», 6-III-1942. AMAE, R-10209/21. "Télégramme», 30-X-1947. AD, Europe 1944-1949, Espagne, vol. 97.

33 «Note verbale de l'Ambassade de l'Espagne au Ministère des Affaires Etrangères», 7-I1943. AGA-MAE, caja 11435.

34 «Informe del Inspector resumiendo las impresiones de su última visita de inspección», 7-VI1943. AMAE, R-7047/17.

Hispania, LXII/2, núm. 211 (2002) 521-560 
miso que no llegó a materializarse en un acuerdo formal, es más ni siquiera se aplicó en sus centros docentes. A la postre, en el terreno de los hechos, se había restablecido básicamente la red de clases implantada en el período republicano y poco más. Esto en cuanto afectaba al territorio metropolitano francés.

En sus posesiones en el norte de África el panorama aún resultaba más decepcionante. Según los informes de los representantes españoles en la zona, la política de asimilación francesa se oponía frontalmente a sus esfuerzos por atraer a los emigrantes. La enseñanza francesa era el principal instrumento de esa política, de forma que la eventual interferencia española provocaba una fuerte hostilidad. La política de asimilación, además de marginar la enseñanza del español y dar una imagen deformada de su país de origen, obligaba a los padres a tomar una difícil decisión: «cuando nuestros pequeños compatriotas más dotados obtienen el Certificado de Estudios Primarios, entonces ha llegado el momento de que el Inspector de Academia comunique a los padres de aquellos que, si desean que el niño continue sus estudios superiores, deben nacionalizarlo francés» ${ }^{35}$.

Tales afirmaciones, apasionamientos aparte, no debían estar muy lejos de la realidad, ya que a mediados de 1943 tan sólo actuaban en la zona 7 maestros españoles: en Argel, Mostaganem, Orán y Casablanca (4). Esa cifra contrastaba con las cifras ofrecidas por las disposiciones oficiales. Es más, ninguno de ellos había recibido autorización para enseñar en escuelas francesas. En Mostaganem se dispuso de un local para las clases de niños y adultos, si bien la asistencia fue escasa y el maestro completó su actividad dando clases de segunda enseñanza a alumnos españoles y franceses. En Argel la proporción de alumnos fue más elevada, pero las clases tuvieron que darse en tres locales distintos. En Orán los locales del Auxilio Social sirvieron como sede para cursos de enseñanza primaria y secundaria. El único lugar donde llegó a establecerse una escuela española graduada fue en Casablanca, que comenzó a funcionar en 1942. En casi todos esos lugares la media de asistencia, sumando los diferentes niveles, superó ligeramente el centenar de alumnos.

\section{PRESIÓN DEL EXILIO Y ANTIFRANQUISMO FRANCÉS}

El contencioso escolar asumió otro cariz tras el final de la guerra mundial. La Francia de la Resistencia iba a lograr que el resto de los países aliados la aceptaran, aunque con ciertas reservas, en la mesa de los vencedores. Los camaradas del Eje habían sido derrotados y la España de Franco se había quedado sin valedores internacionales; es más, se la asimilaba a los regímenes políticos fenecidos. Muy pronto, se levantaría en su contra una amplia campaña de opinión mundial. Los gobiernos franceses estuvieron, inicialmente, en la vanguar-

35 «Sobre Enseñanza Primaria en el Oranesado», 24-VI-1941. AMAE, R-2791/7. 
dia de esa oleada de antifranquismo de la postguerra. La situación afectó a las actividades de los maestros que se encontraban en territorio francés.

Las clases continuaron hasta los últimos meses de 1944, en aquellos lugares que no se vieron afectados por los enfrentamientos bélicos. Con el nuevo año el panorama se modificó sustancialmente. La liberación de Francia tuvo repercusiones directas en este terreno. A principios de 1945 los maestros recibieron nuevas instrucciones, donde se señalaba que su labor era "puramente docente y educativa». Las anteriores referencias al Movimiento Nacional se diluían ahora con la apelación a «los ideales y progreso de nuestra Patria» ${ }^{36}$. Pero esa búsqueda de discrección chocó con las expectativas del sector más militante de las colonias españolas: los exiliados.

El éxodo hacia Francia al acabar la contienda española se vió atenuado por las repatriaciones masivas que se produjeron a lo largo de 1939, favorecidas por los gobiernos de ambos países. La suerte de la población exiliada que permaneció en Francia fue diversa: una parte importante quedó encuadrada en las Compañías de Trabajadores Extranjeros y se distribuyó entre diferentes sectores de la economía de guerra; otra cuantiosa porción fue colocada como mano de obra para la industria y la agricultura; en fin, un número mucho menor acabó enrolada en la Legión u otros cuerpos militares, o bien continuó en los campos de internamiento. Esos españoles no habían sido considerados refugiados políticos, por lo que no se beneficiaron de ningún estatuto específico ${ }^{37}$.

Durante el conflicto mundial sufrieron de nuevo las penalidades de la guerra, esta vez en una tierra extraña que los había tratado con desconfianza cuando no con hostilidad. Pero convencidos de que aquel combate era una continuación de la lucha librada en España contra el fascismo, un buen número de aquellos exiliados se sumaron a las filas de la Resistencia y participaron en la liberación de Francia. Al término de la guerra, ya no eran los desarrapados que habían cruzado la frontera años antes, sospechosos de perturbar la seguridad nacional. Ahora se habían convertido en compañeros de armas, incluso algunos en heroes condecorados por las autoridades francesas. La complicidad, o la tolerancia, de esas autoridades había permitido la organización en suelo francés del movimiento guerrillero que se internó por el valle de Arán con el objetivo de provocar la caída del régimen de Franco. Aquella ofensiva fue un fracaso, pero los exiliados españoles disponían entonces del respaldo de la opinión pública francesa y de una acogida favorable entre los responsables políticos salidos de la Resistencia.

Un decreto de marzo de 1945 les otorgó finalmente la condición de refugiados. Otra disposición tomada en el mes de julio creó el Office central pour les

36 «Instrucciones a los maestros españoles dependientes de la Sección de Relaciones Culturales», II-1945. Boletín Oficial del Ministerio de Asuntos Exteriores, 28-II-1945.

37 Vid. DReYfus-ARMAND, Geneviève: L'exil des républicains espagnols en France. De la guerre civile à la mort de Franco, Paris, 1999, pp. 103 y ss.

Hispania, LXII/2, núm. 211 (2002) 521-560 
réfugiés espagnols, encargado de dotarles de protección jurídica y administrativa. Los exiliados se convirtieron en los años siguientes en un elemento central de las relaciones hispano-francesas. También contribuyó a ello su peso específico dentro del conjunto de la emigración española. En 1945 esa población superaba las 260.000 personas adultas, entre las cuales más de 103.000 habían llegado a Francia después de 1936, casi un 40\% del total. Así pues, esa nueva migración originada por motivos políticos había renovado sustancialmente la colonia, al tiempo que modificó su composición socioprofesional y extendió su implantación geográfica. Una parte importante de ese colectivo se instaló en el sudoeste de Francia, zona tradicional de asentamiento de la población española. Allí se establecieron laboralmente, ahora que tenían facilidades para hacerlo, al tiempo que fundaron asociaciones y revistas culturales para preservar la cohesión e identidad del exilio ${ }^{38}$.

Esas iniciativas del exilio entraron en colisión con las actividades educativas que desplegaba el gobierno español. En mayo de 1945 tan sólo 7 maestros permanecían en sus puestos, el resto había regresado a España o había sido destinado a otros lugares. Su labor docente en escuelas del sur de Francia se suspendió, algunos de los locales que antes acogían las clases subvencionadas por el Estado español fueron ocupados por los exiliados. El gobierno dirigió una nota de protesta a su homólogo francés, exigiendo garantías para que los maestros españoles se reincorporasen a sus puestos. De lo contrario se mostraba dispuesto a cerrar todas las escuelas francesas existentes en su territorio y a impedir su reapertura el próximo curso escolar. La amenaza no se llevó a cabo. El gobierno español aún confiaba en reconducir la tensa relación bilateral aplicando una política de flexibilidad y gestos de buena voluntad. Los centros escolares franceses no sufrieron represalias, incluso crecían los estudiantes matriculados y se consideraba que la acción cultural era una de las principales bazas de su política en España ${ }^{39}$.

Durante 1946 el gobierno francés optó por incrementar la presión sobre el régimen franquista, al tiempo que París se convertía en la capital del exilio republicano al trasladarse allí desde México algunas de sus principales instituciones representativas. A finales de febrero, la frontera entre ambos países quedaba cerrada a iniciativa francesa. Con ello, el ejecutivo galo reforzaba la frágil cohesión de la coalición gubernamental formada por socialistas, comunistas y

38 DReyfus-ARMAND, Geneviève: L'exil des républicains..., pp. 183-199, y «Les réfugies républicains au cœur des relations franco-espagnoles, 1945-1962», Relations internationales, 74 (1993), pp. 153-169.

39 «Maestros españoles en Francia y en el norte de África», 16-V-1945; «Nota al Embajador de España en París», 14-VI-1945. AMAE, R-10212/20. «Propagande des alliés en Espagne. Exposition et remise d'ouvrages français», 9-VII-1945; «Télégramme», 7-XI-1945; "Relations culturelles avec l'Espagne et le Portugal», 10-X-1946. AD, Europe 1944-1960, Espagne, vol. 97. MARTínEZ LILLO, Pedro A.: Las relaciones hispano-francesas en el marco del aislamiento internacional del régimen franquista (1945-1950), Madrid, 1993, pp. 21-28. 
democrata-cristianos, a la vez que adquiría protagonismo en un tema candente de la agenda internacional. Días después, el subsecretario del Ministerio español de Asuntos Exteriores solicitaba un informe sobre los centros docentes franceses en España y españoles en Francia. El desequilibrio era patente. Los primeros no habían visto alterado su funcionamiento y encontraban bastantes facilidades para su desenvolvimiento. En cuanto a la red escolar española, casi había desaparecido tras la liberación. Por el momento no se hizo nada al respecto. A finales de aquel año, la ONU aprobaba sanciones diplomáticas contra el régimen franquista, con el respaldo activo de Francia. Poco después, se planteó la posibilidad de que este país rompiera sus relaciones con España. La medida no llegó a tomarse, entre otras razones por los efectos negativos que ocasionaría a su presencia cultural: por entonces contaba con 2 Institutos franceses, 2 liceos y 16 escuelas, en las que unos 150 profesores impartían clases a varios miles de alumnos españoles ${ }^{40}$. La actitud de enfrentamiento frontal no estaba logrando debilitar a la dictadura ni movilizar los apoyos internacionales deseados, pero sí estaba perjudicando los intereses franceses en España.

La transigencia del gobierno español dió paso, en la primavera de 1947, a una política de firmeza. El contencioso escolar ocupó de nuevo un papel estelar en la escenificación de las desavenencias bilaterales. A principios de abril, la policía desarticuló el Comité Nacional de la F.U.E. También descubrió que su archivo, material de propaganda y algunos explosivos se encontraban en los locales del Liceo Francés de Madrid, donde varios de los detenidos trabajaban como auxiliares de estudio. Francia aparecía implicada, siquiera por pasividad, en las actividades de la oposición antifranquista y, además, el suceso afectaba a uno de sus centros culturales. La polémica no se hizo esperar, la desigual situación de los establecimientos de enseñanza alimentó el resentimiento frente a los agravios franceses.

Junto a la protesta diplomática, el ministro de Asuntos Exteriores encargó a la Dirección General de Relaciones Culturales la preparación de otro informe para el Consejo de Ministros que iba a celebrarse a finales de abril. De la estructura escolar preexistente sólo subsistía la actividad en París, Marsella, Orán y Argelia, más la escuela completa de Casablanca. Esta última, dependiente del Ministerio de Educación Nacional, contaba con 4 maestros y 4 profesores especiales. En el resto de las clases o escuelas estaban destinados otros 6 maestros, que no siempre podían ejercer su trabajo con garantías. También recibían subvenciones del Estado el Solar Español de Burdeos y el Asilo-Escuela de San Fernando en París. La labor docente se había interrumpido en Sète, Beziers, Perpignan, Toulouse, Pau, Lyon, Bayona y Biarritz, «debido a la actuación y preponderancia de los rojos españoles en aquella región, y a la complicidad,

40 "Nota sobre instituciones y profesores franceses en España y españoles en Francia», 7-III1946. AMAE, R-10209/21. «Les oeuvres françaises en Espagne», 20-XII-1946. AD, Europe 19441960, Espagne, vol. 97.

Hispania, LXII/2, núm. 211 (2002) 521-560 
incapacidad o cobardía de las autoridades francesas». En contrapartida, los centros franceses funcionaban con plena normalidad.

Ante tal panorama, se recordaban las conversaciones para un acuerdo de reciprocidad paralizadas por la guerra, proponiéndose aprovechar el incidente del Liceo Francés para retomar esas negociaciones. El Consejo de Ministros aprobó una mayor presión sobre los centros culturales franceses en España si persistían las resistencias para el funcionamiento de las clases y escuelas españolas. En el mes de mayo, la prensa española se hacía eco del asunto, con información posiblemente facilitada por el aparato diplomático. La embajada francesa en Madrid advertía a su gobierno que podía ser el preludio de otra disputa sobre el principio de reciprocidad en materia escolar. Estaba en lo cierto ${ }^{41}$.

\section{DESINTERÉS FRANCÉS VERSUS AMENAZAS DE REPRESALIAS ESPAÑOLAS}

Durante el verano se prepararon instrucciones para el embajador de España en París. A finales de septiembre esas indicaciones quedaban recogidas en una nota enviada al Quay d'Orsay. El gobierno español reclamaba: «a) el restablecimiento de las actividades normales de las escuelas e instituciones españolas en Francia; b) la revisión urgente, sobre la base de la más estricta reciprocidad, de todas las materias que afectaban por una parte a las instituciones y actividades españolas en Francia, y por la otra a la acción cultural francesa en España». Tras enumerar la crítica situación en que se encontraban los maestros, becarios y lectores españoles en Francia, en contraste con las ventajas de que gozaban los establecimientos culturales franceses en España, manifestaba su disposición a acabar con ese desequilibrio. De no garantizarse el cumplimiento de las exigencias formuladas, las autoridades españolas adoptarían una posición menos benévola e indulgente hacia los centros franceses. El curso escolar estaba a punto de empezar. Los franceses hicieron notar que esa actitud conminatoria resultaba contraproducente con los pasos dados para negociar una reapertura de la frontera, o con la postura de reserva adoptada por su gobierno en la ONU ante la «cuestión española». El carácter de ultimatum que tenía la comunicación aludida se suavizó. Como muestra de flexibilidad los centros franceses pudieron comenzar sus clases, a condición de abordar con celeridad la cuestión de la reciprocidad ${ }^{42}$.

41 «Establecimientos culturales españoles en Francia y franceses en España», 24-IV-1947. AMAE, R-10209/21. "Télégramme», 15-V-1947; "Article d"“Arriba” relatif à l'incident du Lycée Français et à la situation en France des écoles espagnoles», 1-V-1947. AD, Europe 1944-1960, Espagne, vols. 2 y 97.

42 «Nota para la Dirección General de Relaciones Culturales», 27-VIII-1947; «Nota cursada al Quay d'Orsay sobre las relaciones culturales entre España y Francia», 29-IX-1947; «Embajador de España en París al Director General de Relaciones Culturales», 1-X-1947. AMAE, R-10209/21. «Télégramme», 30-IX-1947; "Ambassadeur d'Espagne au Secrétaire Générale du Ministère des Affaires Etrangères», 1-X-1947. AD, Europe 1944-1960, Espagne, vol. 97. 
A lo largo de octubre se sucedieron las conversaciones entre funcionarios de ambos países, una vez rebajado el tono apremiante de la primera nota española. El gobierno francés reconocía a los establecimientos culturales españoles «un tratamiento fundado sobre el principio de la reciprocidad y la igualdad». Pero a la hora de materializar esa declararación genérica, los representantes franceses se mostraban reacios a transigir con las aspiraciones españolas. La demanda de contar con centros de enseñanza similares en número e importancia a los que Francia disponía en España, al menos en el plano teórico, fue contestada con otra fórmula que contemplaba la creación de centros en correspondencia con las «necesidades reconocidas de la colonia española y la difusión de su cultura». Sin duda eso limitaba las expectativas del gobierno español, dadas las características de su emigración en el país vecino. De hecho, se apuntaba que era imposible acceder a sus peticiones concretas sobre la apertura de centros en varias poblaciones francesas, ya que las tendencias políticas imperantes en ellas lo desaconsejaban. Asimismo, los negociadores galos realizaron diversas matizaciones a las reclamaciones de su interlocutor, desviando así la atención sobre el tema de fondo ${ }^{43}$.

La diplomacia francesa era consciente de la fragilidad jurídica de su posición. La autonomía con que actuaban sus centros culturales en España antes de 1939 no estaba amparada por ningún precepto legal. Los únicos acuerdos bilaterales existentes eran las notas intercambiadas por ambos gobiernos el $21 \mathrm{y}$ el 23 de septiembre de 1940, cuyo contenido otorgaba a la parte española unos derechos que ahora preferían obviarse. Además, esos acuerdos solo contemplaban una autorización provisional para el funcionamiento de sus centros, que podía ser revocada en cualquier momento. Dadas las circunstancias, la situación de hecho era la que mejor se ajustaba a sus intereses: su red docente continuaba sus actividades con normalidad, mientras que a cambio se reconocía la posibilidad a los españoles de tener escuelas en Francia, sin mayores precisiones. Las autoridades españolas se contentaron, por ahora, con comprobar que el contencioso escolar representaba una espada de Damocles que podía manejarse de forma discreta para presionar a Francia ${ }^{44}$.

Lo importante no era el asunto en sí, sino su rentabilidad política. Parece demasiado casual que, después de tres años sin abordar el problema, volviera a suscitarse casi al mismo tiempo que el gobierno francés autorizaba la reunión de las Cortes republicanas en la localidad de Blois. Esa autorización fue suspendida, nueva coincidencia, en fechas análogas al desenlace de las conversaciones en materia cultural. En ellas nunca se mencionó una relación directa

43 «Télégrammes», 1, 2, 3, 8-X-1947; «Note pour M. Chauvel», 11-X-1947. AD, Europe 1944-1960, Espagne, vol. 97. «Remite nota sobre régimen establecimientos culturales españoles en Francia», 29-X-1947. AMAE, R-10209/21.

44 «Télégrammes», 14 y 30-X-1947; «Statut des Etablissements d'enseignement français en Espagne», 15-X y 6-XI-1947. AD, Europe 1944-1960, Espagne, vols. 97 y 98 . «Embajador de España en París al Ministro de Asuntos Exteriores», 29-X-1947. AMAE, R-10209/22.

Hispania, LXII/2, núm. 211 (2002) 521-560 
entre ambos factores, pero está claro que los intereses culturales y económicos de Francia en España servían para moderar las inclinaciones antifranquistas de su gobierno.

En febrero de 1948 se reabrió la frontera hispano-francesa. El enfrentamiento frontal con el régimen franquista no había logrado sus objetivos y había resultado contraproducente para la influencia de Francia en España. Uno de los medios empleados para reducir la crispación bilateral e ir preparando un clima de mayor confianza fue el relanzamiento de las relaciones culturales. Del lado francés, se recabó información sobre el lugar que ocupaba la enseñanza de su lengua en España, al tiempo que comenzó a plantearse la reconstrucción de la Casa de Velázquez destruida durante la guerra civil ${ }^{45}$. Por parte española, el esfuerzo adquirió mayor relieve, acompasándose con la reorganización de sus servicios culturales en aquel país. Esa actuación se plasmó en la recuperaciọ́n del control sobre el Colegio de España en la Ciudad Universitaria de París, la intensificación del intercambio de profesores, estudiantes y publicaciones, y la lenta pero progresiva normalización de la enseñanza española en Francia. Para la resolución de este último asunto los primeros escollos tenían su origen del lado español: la carencia de divisas y las deficiencias organizativas del aparato diplomático. Entre los meses de abril y junio volvía a solicitarse información sobre la situación de las escuelas, los gastos previstos para su mantenimiento y las dificultades que cabía encontrar para su funcionamiento. Los datos comenzaron a llegar en el transcurso del verano ${ }^{46}$.

Por entonces, ya no eran de prever incidentes motivados por la reapertura de las escuelas, pues «la situación política ha mejorado sensiblemente y la importante población de refugiados políticos va perdiendo con celeridad su antigua virulencia». Las autoridades locales si bien no favorecerían su restablecimiento tampoco se opondrían. Se recomendaba, no obstante, actuar con prudencia. Aunque no debían descartarse otras opciones para casos puntuales, la fórmula más viable a corto plazo era la practicada desde 1932, es decir, impartir clases complementarias en escuelas francesas o en centros españoles habilitados al efecto. También era la que requería un menor desembolso. Por otro lado, convenía resolver el problema de la falta de validez académica para esa

45 «Place du Français dans l'enseignement en Espagne», 16 y 23-X-1947; "Casa Velazquez», 3-XII-1947. AD, Relations culturelles, Enseignement 1945-1947, vols. 52 y 55. DelaunAY, JeanMarc: Des palais en Espagne. L'École des hautes études bispaniques et la Casa de Velázquez au cour des relations franco-espagnoles du XX siècle (1898-1979), Madrid, 1994, pp. 390 y ss.

46 «Embajador de España en París al Director General de Relaciones Culturales», 18-III-1948; Ordenes del Ministerio de Asuntos Exteriores: 5-IV, 31-V y 25-VI-1948. AMAE, R-10209/22. "Questions des relations culturelles avec l'Espagne», 2-VI-1948. AD, Europe 1944-1960, Espagne, vol. 98. La reorganización de los servicios culturales en Francia fue encomendada al catedrático Luis Díez del Corral, recien nombrado Consejero Cultural. «M. del Corral, nouvel attaché culturel à la Délégation espagnole en France», 4-V-1948. AD, Relations culturelles, Enseignement 1948-1961, vol. 225.

Hispania, LXII/2, núm. 211 (2002) 521-560 
labor docente, al carecer España de un diploma de estudios primarios equivalente al Certificat d'Études francés. Como criterio de actuación inmediata, se proponía recurrir a la vía del ejemplo, extendiendo a otras localidades las enseñanzas que impartían maestros españoles en Marsella y París. Así se desmontarían con hechos las "pretendidas dificultades del ambiente político e incluso de orden público» que esgrimían los franceses, argumentación que solo era una excusa para seguir desarrollando su política de asimilación sobre la población española ${ }^{47}$.

A partir de tales presupuestos quedaron esbozadas las líneas básicas de un plan de acción. El primer paso consistiría en restablecer la red docente existente en 1943, comenzando por la escuela de Béziers. Simultáneamente, se someterían al gobierno francés una serie de reclamaciones: « $1^{\circ}$ Autorización de principio para la automática reapertura de nuestras escuelas primarias y cursos de español, y para la creación de aquellas otras que en lo futuro se estimen necesarias; $2^{\circ}$ Equiparación numérica estricta entre la cifra de profesores franceses actuantes en España en establecimientos de primera o segunda enseñanza y sus colegas españoles en Francia, con expedición de los correspondientes documentos de identidad; $3^{\circ}$ Instrucciones categóricas a las autoridades locales francesas para la solución de eventuales dificultades burocráticas y, en especial, para el suministro de locales, publicidad, programas, etc.; $4^{\circ}$ Notificación oficial con información sobre cada persona de los nombramientos que se efectuen por ambas partes; $5^{\circ}$ Equiparación en su validez legal de los efectos y aprovechamiento de los títulos, grados y certificados expedidos por nuestros establecimientos y por los franceses». Idénticas facilidades cabía solicitar en los territorios de Marruecos y Argel. Todas esas demandas debían recogerse en la negociación de un acuerdo cultural valedero por cinco años. Para hacerlo efectivo, era preciso estar dispuestos a aplicar una política de restricciones que contemplase incluso la paralización de los centros franceses en España ${ }^{48}$.

La negociación del acuerdo bilateral iba a demorarse, ante la falta de interés por parte francesa. La reapertura de la frontera alentaba un clima de mayor conciliación y no era el momento de provocar un foco de tensión diplomática. Por otro lado, el número de maestros españoles se ampliaba paulatinamente. En 1950 se había elevado a 10: París (2), Marsella (2), Béziers, Biarritz, Lyon, Argel,

\footnotetext{
47 «Informe sobre el establecimiento de escuelas españolas en Francia», 7-VIII-1948; «Establecimiento de escuelas españolas», 4 y 7-IX y 2-X-1948; «Restablecimiento de escuelas españolas en Francia», 16-IX-1948. AMAE, R-8586/17 y 20 y R-10209/22.

48 «Informe de la Dirección General de Relaciones Culturales», 29-IX-1948; «Nota verbal», 2-X-1948; "Restablecimiento normalidad establecimientos docentes españoles en Francia», 8-XI1948; "Consejero Cultural en París al Director General de Relaciones Culturales» y "Plan de necesidades urgentes para la acción cultural próxima en París», 15-XII-1948; «Nota de Asesoría para las conversaciones que sobre enseñanza de los españoles en África se inician con Francia», s.f. AMAE, R-10209/22.
}

Hispania, LXII/2, núm. 211 (2002) 521-560 
Orán y Mostaganem, a los que se añadían los destinados en la escuela de Casablanca ${ }^{49}$. Sin embargo, antes de acabar el año estalló un nuevo conflicto.

El maestro español en Béziers fue amenazado de expulsión por no cumplir la legislación escolar, que le exigía el reconocimiento por la administración francesa de sus títulos universitarios. Además, se le obligaba a admitir en sus clases sólo a alumnos que poseyeran la nacionalidad española. La protesta no se hizo esperar, acompañada de una amenaza velada a través de la petición de una lista de los alumnos inscritos en centros franceses en España que no poseyeran la nacionalidad francesa. La disparidad entre las condiciones en que se desenvolvía la actuación docente en uno y otro país volvía a adquirir proporciones alarmantes, como reconocía el propio representante diplomático francés en España. El ministro de Asuntos Exteriores español notificó el caso a su colega de Educación Nacional, pidiéndole que considerase la posible aplicación de medidas de retorsión sobre los intereses culturales franceses. Sugería asimismo aprovechar cualquier ocasión para «dejar constancia de la interinidad del estado de cosas en que actualmente viven los establecimientos franceses en España, y la desproporción numérica que existe entre los centros españoles en Francia y los similares franceses en nuestro país». Las conversaciones mantenidas en París en febrero de 1951, entre el Consejero Cultural español y representantes franceses de los ministerios de Asuntos Exteriores y Educación, atenuaron las consecuencias del incidente. La expulsión quedó anulada, transmitiéndose a las autoridades españolas los requisitos que deberían cumplir sus maestros para impartir clases en Francia ${ }^{50}$.

En aquellas mismas fechas se produjo la normalización de las relaciones diplomáticas entre ambos países, con el nombramiento de un embajador francés en Madrid, circunstancia que atenuó las tensiones suscitadas en el contencioso escolar. La ocasión, no obstante, fue aprovechada por el gobierno español para plantear varias cuestiones pendientes. Junto al alejamiento de la frontera de los refugiados más peligrosos, o el cese de la campaña de los medios de comunicación contra el régimen franquista, se solicitaba el pleno funcionamiento de las escuelas españolas en Francia y el norte de África. Igualmente, se exigía la restitución del inmueble de la Avenue Marceau, en poder del gobierno vasco en el

49 «Nota informativa», 20-IV-1950. AMAE, R-7047/17. La reanudación de las actividades escolares en las diversas localidades francesas puede seguirse a través de AMAE, R-10212/33 y R$10213 / 2,3$ y 12. En cuanto a la escuela de Casablanca, aún no estaban acabadas las obras de construcción empezadas hacía diez años. La matrícula de alumnos españoles rondaba el centenar, más otra cifra similar de estudiantes que asistían a los cursos para extranjeros. «Informe del inspector de escuelas españolas en el extranjero tras su visita a la zona francesa del protectorado de Marruecos», 2-IV-1951. AMAE, R7047/17.

so «Ecole espagnole de Béziers», 21-XI y 27-XII-1950, 9-I-1951; «Note verbale», 21-XII1950; «M. Lorenzo Salgado», 8-II-1951; "Attribution d'une carte de résident à M. L. Salgado», 19V-1951. AD, Relations culturelles, Enseignement 1948-1961, vols. 225 y 228. «Ministro de Asuntos Exteriores al Ministro de Educación Nacional», 21-XII-1950. AMAE, R-10209/22. 
exilio. Este último litigio, que también venía de tiempo atrás, motivó otro acuerdo del Consejo de Ministros para cerrar los centros franceses en España si no se atendía su demanda. Tampoco esta vez las represalias llegaron a materializarse, pero en el verano de 1951 el Estado español recuperaba el edificio ${ }^{51}$.

¿Y las escuelas? Ese mismo año se habían reiniciado los viajes de inspección, interrumpidos desde el final de la guerra mundial. La impresión recogida tras el primero de ellos a las localidades del mediodía francés distaba de ser halagüeña. En Biarritz y Béziers los cursos se impartían a un número reducido de alumnos, en locales casi improvisados y sin apenas material pedagógico. No se habían retomado las clases en las escuelas francesas. En el resto de las localidades donde antes se desarrollaban actividades docentes (Sète, Pau, Perpignan), la implantación de los refugiados españoles continuaba desaconsejando su reanudación ${ }^{52}$.

\section{UNA HISTORIA INTERMINABLE, O MUCHO RUIDO Y POCAS NUECES}

Lo cierto es que más allá de su utilización como arma arrojadiza en la negociaciones diplomáticas, las escuelas no eran un tema relevante para las relaciones bilaterales. A lo largo de la década de los años cincuenta esas relaciones fueron mejorando. La tolerancia de las autoridades francesas hacia las actividades de los exiliados dejó paso a un mayor control, para acallar las reiteradas quejas de sus vecinos meridionales. Francia apoyó el ingreso de España en foros internacionales como la UNESCO, la ONU o la OECE. En 1953 se otorgó un importante crédito al gobierno español para apoyar su equipamiento industrial. En fin, pese a sus rivalidades previas, el imparable proceso independentista llevó a ambos países a alinear sus políticas respecto a Marruecos. En cambio, en lo referente a las escuelas españolas en Francia no hubo avances significativos.

La precariedad de las condiciones que rodeaban esa actividad docente se ponía de relieve en un informe de la embajada en París, enviado en junio de 1952. La población escolar que atendían ascendía a poco más de 300 alumnos. La escuela de Lyon estaba sin titular desde el año anterior. Salvo alguna excepción, seguía sin lograrse que los maestros pudieran dar clases en grupos escolares franceses con presencia de hijos de españoles. Las autoridades francesas daban buenas palabras, pero a la hora de la verdad se desentendían u ofrecían como única fórmula viable el acatamiento de la normativa escolar del país. Eso

S1 «Aide-Mémoire espagnol relatif aux questions pendantes», 2-II y 13-III-1951; «Immeuble de l'Avenue Marceau», 24-IV-1951; «Télégrammes», 26-IV y 2, 511 y 12-V-1951; «Note de la Direction Générale des Relations Culturelles», 30-IV-1951. AD, Relations culturelles, Enseignement 1948-1961, vol. 225, y Europe 1944-1960, Espagne, vol. 207.

52 «Viaje Sr. Saez inspeccionar escuelas Francia», 7-VI-1951; «Informe del inspector de las escuelas españolas en el extranjero, luego de su visita al mediodía de Francia», 6-VII-1951. AMAE, $\mathrm{R}-7047 / 17$.

Hispania, LXII/2, núm. 211 (2002) 521-560 
suponía atenerse a la circular de 12 de julio de 1939, que trasladaba las decisiones a los responsables académicos locales y a los directores de escuela. Los maestros extranjeros era asimilados a monitores, aplicándoles un régimen de derecho interno, sin referencia de ningún género a las normas internacionales $\mathrm{ni}$ a la situación de la enseñanza del francés en el país respectivo. En resumen, «la realidad pura es que no encontramos más que dificultades para nuestros planes; nuestros maestros son molestados con triquiñuelas administrativas, no se pueden ampliar las enseñanzas, intentan reducir su status al de monitores privados, en fin, tratan de recortar en lo posible nuestra postura cuando poseemos en España tantos medios de actuar, o por lo menos de poder indicar diplomáticamente a los franceses que la reciprocidad tiene sus exigencias y que es exigible». La respuesta desde Madrid fue que el asunto de las escuelas en Francia y Norte de África estaba pendiente de una "reorganización a fondo», que requería una negociación previa con el Ministerio español de Educación Nacional ${ }^{53}$.

Durante aquel año volvió a sondearse la viabilidad de llegar a un acuerdo cultural. Desde la óptica francesa esa opción presentaba más inconvenientes que ventajas. Aunque sus centros en España no disponían de un reconocimiento jurídico que respaldara su labor, una eventual negociación que garantizara a los españoles una reciprocidad de trato, ahora inexistente, implicaría serias dificultades. La experiencia práctica les demostraba, a fin de cuentas, que «el clima de las relaciones políticas y culturales era más importante que los textos legislativos o los acuerdos diplomáticos para asegurar la salvaguardia de los establecimientos franceses en el extranjero" ${ }^{54}$.

Las propuestas de modificar una situación considerada a todas luces injusta se sucedieron. Los informes enviados a lo largo de 1953 por los representantes españoles en Francia repetían demandas de corte similar a las anteriores. Los cursos impartidos en Beziers tenían unos 100 alumnos, unos 60 en Biarritz, unos 180 en Marsella y algo más de 300 en el Patronato de Saint Denis en París. La plaza de Lyon continuaba sin cubrir. Tan sólo el maestro destinado en la capital daba clases en un centro escolar francés de Aubervilliers, zona de asentamiento de la emigración económica. También habían vuelto a organizarse colonias veraniegas en La Valette (para niñas) y en Nogentel (para niños), junto a expediciones estivales a España. Los promotores de esas actividades fueron los religiosos del Real Patronato de Santa Teresa de Jesús en París, con la colaboración de la Sección Femenina de Falange y del Frente de Juventudes. Pero una acción de alcance tan limitado era incapaz de fomentar el sentimiento de nacionalidad entre la comunidad española. Para variar, se solicitaba iniciar

s3 «Nota de la Embajada de España en París», 6-VI-1952; «Escuelas en Francia», 4-X-1952. «Ministère de l'Education Nationale à l'Ambassadeur de l'Espagne», 3-VI-1953. AMAE, R10212/20 y R-8586/18.

54 «Comisión Permanente de la Junta de Relaciones Culturales», 21-III-1952. AMAE, R11051/1. "Note sur le statut des etablissements français en Espagne», 20-XI-1952. AD, Europe 1944-1960, Espagne, vol. 207. 
gestiones para «un mejoramiento del actual "statu quo", con un reconocimiento formal por parte del gobierno francés de los derechos que el propio español no le niega en su territorio» ${ }^{55}$. Y vuelta a empezar.

A comienzos de 1954, otra petición de datos sobre la actividad docente, su alcance y obstáculos. El panorama casi invariable, salvo para empeorar. Ahora el único grupo escolar francés donde daba clases un maestro español le notificaba la imposibilidad de mantener esa labor. La causa de fondo era que la dirección del centro había recaído en un militante comunista, según las fuentes españolas. La falta de base legal impedía una reclamación efectiva. Tales restricciones sólo podían superarse mediante un acuerdo que diese al gobierno español las mismas prerrogativas que tenían los centros franceses en España. El diagnóstico resultaba clarificador: «nuestra colonia en Francia se compone en su inmensa mayoría de familias de posibilidades económicas muy reducidas y de situación social precaria en muchos casos. La función de las clases de español no tiene más finalidad que permitir (...) que los jovenes españoles conserven su propia lengua y puedan sentirse incorporados a su comunidad nacional, aunque hay que reconocer que a la larga son absorbidos por el medio ambiente. El Estado español debe sin embargo hacer lo posible para que, en el momento que una posible elección se plantee, los españoles de origen puedan estar formados suficientemente en su lengua y cultura para poder elegir con elementos de juicio» ${ }^{56}$.

En los últimos meses de ese año se entablaron nuevas conversaciones con la embajada francesa en Madrid, que exponía a su vez el deseo de que se regularizase el estatuto de los establecimientos franceses en España y sus profesores contasen con una tarjeta de identidad. Basta echar un vistazo al documento preparado por el Agregado Cultural de la embajada francesa sobre la evolución y estado de esos centros, y compararlo con los confeccionados por la parte española, para apreciar las sensibles diferencias existentes entre ambos países en la relevancia concedida a la accción cultural. La cantidad y calidad de la información recopilada, la profundidad de los análisis, eran bastante ilustrativos de algunas de las razones por las que Francia siempre había llevado una clara ventaja en el contencioso escolar ${ }^{57}$.

Para empezar, sus funcionarios mostraban una continuidad y capacidad en su trabajo de la que carecían los españoles, quienes constantemente repetían las

55 «Sobre situación jurídica enseñanzas de español en Francia», 17-VII-1953; «Resumen de las actividades escolares españolas en Francia», 17-IX-1953. AMAE, R-8586/18. Real Patronato de Santa Teresa de Jesús en París. Memoria 1954-1955, París, 1955.

56 «Personal docente de las instituciones españolas en Francia», 4-III-1954; «Dificultades que hallen en el desarrollo de su labor cultural», 11-III-1954; "Status" personal docente y enseñanzas de español en Francia», 8-IV-1954. AMAE, R-8586/16.

57 «Compte-rendu d'une reunion tenue chez M. de la Tournelle sur les problemes culturelles franco-espagnols», 29-X-1954; «Rapport sur l'ensemble des oeuvres françaises en Espagne», 24-XI1954. AD, Europe 1944-1960, Espagne, vol. 208, y Relations culturelles, Enseignement 19481961, vol. 225.

Hispania, LXII/2, núm. 211 (2002) 521-560 
mismas gestiones para llegar a conclusiones similares con un desenlace análogo: dejar las cosas como estaban tras montar un poco de barullo administrativo. Los medios económicos puestos en juego tampoco tenían nada que ver, en el caso español eran lisa y llanamente miserables. Los objetivos también diferían considerablemente, si los franceses aspiraban a que sus centros fuesen un vivero donde se formasen los dirigentes españoles, estos últimos ni siquiera era capaces de asegurar una mínima presencia educativa y cultural entre los miles de emigrantes de su país asentados al otro lado de los Pirineos. A tales premisas habría que añadir la escasa voluntad política manifestada por el gobierno español para enderezar los desequilibrios bilaterales aludidos, de los que tan insistente y amargamente se quejaban sus funcionarios. Y continuarían haciéndolo durante varios años mas, sin que ello aparejase variaciones sustanciales en el estado de la enseñanza española en Francia. Tampoco se alcanzó la firma de un acuerdo cultural que ofreciera garantías para su desarrollo, pese a los avances en las negociaciones entabladas en ese sentido ${ }^{58}$.

En octubre de 1955, el gobierno español aprobó un nuevo reglamento para las escuelas de enseñanza primaria y los intitutos de enseñanza media en el extranjero, que hasta entonces se regían por las disposiciones legales establecidas durante la II República. Las escuelas pasaban de la órbita del Ministerio de Asuntos Exteriores al de Educación Nacional, que se encargaría en lo sucesivo de su organización interna, disciplina, régimen e inspección, además de nombrar a sus cargos directivos y personal docente ${ }^{59}$. Pero ese afán de reforma normativa no se acompañó de una preocupación paralela en el estímulo de las actividades docentes, al menos para el caso francés. A comienzos de los años sesenta la presencia docente española en Francia había decrecido ligeramente, a pesar del incremento de la corriente migratoria hacia el país vecino. La escuela de Lyon se había suprimido finalmente. En Biarritz se encontraban suspendidas las clases desde principios de 1958, debido al fallecimiento del titular de la plaza sin que se nombrara a un sustituto. Las instalaciones de la escuela de Béziers se encontraban en un estado deplorable. Tan sólo los maestros destinados en Marsella y en La Pleine-Saint Denis en París mantenían una actividad esco-

58 Vid. a título de ejemplo, «Correspondencia entre el Secretario General Técnico del Ministerio de Educación Nacional y el Director General de Relaciones Culturales», 8 y 9-VII-1955; «Actividades maestro español en Biarritz», 30-IX-1955; "Ministro de Asuntos Exteriores al Embajador de España en París», 10-X-1955; "Ampliación actividades escolares maestro español en Biarritz», 19-X1955; "Jefe de Política Cultural de Europa al Jefe de la Sección de Institutos, Escuelas y Lectorados», 3-XI-1945. AMAE, R-10209/22 y R-8586/18. «Eventuelle négociation d'un Accord Culturel francoespagnol», 23-XII-1957; «Accord culturel franco-espagnol», 19-II y 22-VII-1958. AD, Europe 19441960, Espagne, vol. 208, y Relations culturelles, Enseignement 1948-1961, vol. 225.

59 «Ministerios de Asuntos Exteriores y Educación Nacional. Decreto de ambos Departamentos de 21 de octubre de 1955, por el que se aprueba el Reglamento de las escuelas españolas de Enseñanza Primaria en el extranjero». Boletín Oficial del Estado, 25-XI-1955. Sobre la tramitación de esa medida y las desavenencias que provocó entre ambos ministerios vid. AMAE, R-8586/24, R$10212 / 18$ y R-11051/5. 
lar digna de tal nombre, aunque tampoco lo hacían en las mejores condiciones ni con medios suficientes. El responsable de la Dirección General de Relaciones Culturales reconocía que llevaban «una vida precaria», y que se necesitaba un fuerte incremento presupuestario para dinamizar su funcionamiento ${ }^{60}$.

El gobierno español no estaba dispuesto a asumir tales gastos. Es cierto que las arcas del Estado no atravesaban una coyuntura propicia, máxime cuando el Plan de Estabilización de 1959 impuso entre sus objetivos el control del gasto público y la reducción de su déficit global, y cuando la devaluación de la peseta había incrementado el coste de los servicios en el exterior. Pero también lo es que en idéntica situación se encontraba la acción cultural en Marruecos y, sin embargo, tras la independencia del país magrebí se realizó allí un esfuerzo presupuestario considerable ${ }^{61}$. En resumidas cuentas, las escuelas españolas en Francia habían actuado como un medio intermitente de presión diplomática respecto al país vecino. La desigualdad de la red escolar de cada país en el otro era un argumento a emplear cuando surgían motivos de fricción bilterales. Otra cosa bien distinta era el papel que habían jugado en la preservación de los sentimientos nacionales y la lengua española entre los emigrantes y sus descendientes. Al margen de declaraciones de principios, de protestas diplomáticas, de amenazas nunca materializadas contra los intereses franceses, la oferta educativa española hacia sus emigrantes era casi una ficción. En el terreno práctico, apenas se hacía nada para evitar que perdieran los vínculos culturales con su país de origen, para contrarrestar su integración en el sistema escolar del país de acogida. La batalla contra la política de asimilación francesa por la vía de la enseñanza se daba por perdida antes de librarla, aunque se aderezase con sentidas críticas hacia el obstruccionismo de sus interlocutores.

\section{REACTIVACIÓN DE LA EMIGRACIÓN ECONÓMICA Y DEMANDAS DE ATENCIÓN EDUCATIVA}

La emigración española hacia Francia adquirió una renovada intensidad desde mediados de los años cincuenta, alcanzando el mayor volumen de desplazamientos a mediados de la década siguiente. El gobierno español se había mostrado reacio anteriormente a favorecer esa corriente migratoria, e incluso a negociar nuevos acuerdos que remplazasen al convenio suscrito en $1932^{62}$. Pero

60 «Escuela española de Biarritz», 12-III-1958, 29-I y 21-II-1959; «Informe», 12-III-1959; «Situación escuela Béziers», 10-XII-1959. AMAE, R-10212/20, 21 y 33 y R-10213/3. RUIZ MORALES, Jose Miguel: «Teoría de las relaciones culturales», Cuadernos de la Escuela Diplomática, año I, vol. 2 (1960), p. 97.

61 JevenOIS ACILlona, Pablo de: «Los Centros Culturales y Educativos en el exterior 1942-1991», en La Dirección General de Relaciones Culturales y Científicas 1946-1996, Madrid, 1997, pp. 179-181.

62 «Télégramme», 20-V-1952; «Espagnols en France», 1-VII-1955. AD, Europe 1944-1960, Espagne, vol. 219. 
las necesidades de la economía española, unidas a una coyuntura de fuerte aceleración del crecimiento económico en Europa occidental, modificaron esa conducta. La fase expansiva de las economías europeas, unida a su lento progreso demográfico, motivaron la necesidad de recurrir a mano de obra extranjera. Esa mano de obra se reclutó en los países del sur del continente: Italia, España, Yugoslavia y Portugal. Los emigrantes ocuparon los trabajos más pesados y peor remunerados, pero esa dureza era compensada con altos salarios en relación con sus países de origen, trabajo seguro y mejores condiciones sociales (sanidad, educación, seguridad social,...).

En España existía una población laboral excedentaria, debido al incremento demográfico y la decadencia del sector agrícola. El fenómeno se tradujo en la emigración del campo a la ciudad y del centro a la periferia, pero la oferta de trabajo de las ciudades y. los centros turísticos era inferior a las nuevas demandas de empleo. La emigración a Europa se contempló entonces como una solución a esa conflictiva situación. El efecto de emulación de los primeros emigrantes, que difundían una visión de bienestar muy alejada de las penurias de la España del momento, hizo el resto. Para estimular la corriente migratoria fueron anulados los controles que previamente la obstaculizaban, al tiempo que aparecían organismos encargados de fomentar y regular ese flujo de población. En julio de 1956 se creó el Instituto Español de Emigración, adscrito primero a la Presidencia del Gobierno y más tarde al Ministerio de Trabajo. En los años siguientes se suscribieron convenios con varios países europeos. La emigración de los años sesenta iba a paliar los efectos sociales del Plan de Estabilización, dar más salidas al fuerte éxodo rural y obtener divisas para compensar las pérdidas por importaciones de la balanza comercial63.

Entre 1957 y 1961, España y Francia firmaron varios acuerdos a través del Instituto Español de Emigración y el Office National d'Immigration, que abordaban aspectos como los regímenes de salarios, seguridad social, impuestos o reagrupación familiar para trabajadores permanentes, además de cuestiones más específicas que concernían a la emigración de carácter temporal y los trabajadores fronterizos ${ }^{64}$. El fuerte desarrollo económico francés precisaba de nuevo el aporte de mano de obra extranjera para mantener el ritmo ascendente. España volvió a proporcionar uno de sus principales focos de aprovisionamiento. Si el

63 FerNÁNDez Asperilla, Ana: «La emigración como exportación de mano de obra: el fenómeno migratorio a Europa durante el franquismo", Historia Social, 30 (1998), pp. 63-81; PALAZÓN FERRANDO, Salvador: «Reanudación, apogeo y crisis de la emigración exterior española (19461995)", Ería, 45 (1998), pp. 37-53; VILAR, Juan B. y VILAR, María J.: La emigración española a Europa en el siglo XX, Madrid, 1999. Sobre la modificación de la política migratoria española en los años cincuenta y sus repercusiones sobre la intensificación de esa corriente hacia Europa, vid. BAEZA SANJuÁn, Ramón: Agregados Laborales y acción exterior de la Organización Sindical Española. Un conato de diplomacia paralela (1950-1961), Madrid, 2000, pp. 175-209.

64 Sobre el marco jurídico-institucional establecido entonces vid. DIAZ-PLAJA, Guillermo: La condición emigrante. Los trabajadores españoles en Europa, Madrid, 1974, pp. 245 y ss.

Hispania, LXII/2, núm. 211 (2002) 521-560 
censo francés de 1954 estimaba que la población española era de 288.923 personas, en 1962 la cifra llegaba a las 441.658 y en 1968 alcanzaba las 607.184. La colonia española ocupó entonces la cabeza de la población extranjera allí asentada, con un porcentaje del $23 \%$. A ello se añadía una emigración estacional que cubría el $90 \%$ de las necesidades francesas. Una parte importante de los desplazamientos se produjo al margen de los circuitos oficiales españoles, lo que dió lugar a sucesivos procesos de regularización por parte de las autoridades francesas.

La nueva corriente de población se asentó preferentemente en las zonas industriales del noreste del país y, con mayor incidencia, en la región parisina. La perspectiva del retorno en un período de tiempo no muy lejano era común a ese colectivo de emigrantes. Su horizonte consistía en trabajar duro, ahorrar todo el dinero posible, volver a España con lo ganado y elevar allí su posición social gracias a aquel capital. Sus relaciones laborales se desarrollaron en dos escenarios: el paisaje industrial de los obreros que trabajaban en las fábricas y el medio burgués de quienes estaban empleados en el servicio doméstico. En el primer caso se trataba de trabajadores varones, ocupados en buena medida en las industrias del automóvil, las obras públicas y la construcción de la región parisina, o en las industrias metalúrgicas, siderúrgicas y químicas del norte y el este del país. En el segundo, la mayor proporción eran empleadas femeninas, agrupadas en los barrios burgueses de la capital francesa. Se habían producido pues cambios en las zonas de asentamiento y en la distribución de la población activa. El centro de gravedad dejaba de estar en el mediodía francés y las regiones fronterizas para desplazarse hacia el norte, el predominio de los empleos agrícolas perdía peso entre la emigración permanente en beneficio de los sectores industrial y de servicios. Esa renovación del caudal migratorio también acarreó una pérdida de influencia de los refugiados políticos en el seno de la colonia española ${ }^{65}$.

¿Qué actividad desplegó el régimen español para atender las necesidades educativas de la nueva corriente migratoria? El gobierno mantuvo una retórica de preservación de la identidad cultural de los emigrantes, de expectativa del retorno a su país de origen, que favorecía sus intereses de dirigir hacia España

\footnotetext{
65 «Les emigrés espagnols à l'heure de Paris» y «Les travailleurs espagnols en France», Revista Franco-Española, 108 y 109 (1965), pp. 29-31 y 12-13; AGUILO, Federico et CAPPANERA, Raoult: "Enquête auprès de quelques Espagnols emigrés dans les banlieux de Barcelona et de Paris», Emigration et syndicalisme, supplément à Masses ouvrières, 246 (1968), pp. 12-69; HERMET, Guy: Los españoles en Francia, Madrid, 1969, pp. 29-39; SÁNCHEZ LÓPEZ, Francisco: Emigración española a Europa, Madrid, 1969, pp. 99-137; RUBIO, Javier: La emigración española..., pp. 294-370; PARRA LUNA, Francisco: La emigración española..., pp. 53 y ss.; BACHOUD, Andrée et DREYFUS-ARMAND, Geneviève: «Des Espagnols aussi divers que nombreux, Paris 1945-1975», en Le Paris des étrangers, Paris, 1994, pp. 55-76; BABIANO, José: «El vínculo del trabajo: los emigrantes españoles en Francia en los treinta gloriosos», Migraciones E Exilios, 2 (2001), pp. 9-37; DrEYFus-Armand, Geneviève: L'exil des républicains..., pp. 297-303.
}

Hispania, LXII/2, núm. $21 \cdot 1$ (2002) 521-560 
el ahorro de ese colectivo. Así, entre los cometidos del Instituto Español de Emigración figuraba "promover cuantas iniciativas se encaminen a valorar y proteger la emigración española en el orden moral, económico y cultural». Por otro lado, a principios de 1960 , se extendieron a las escuelas españolas en el extranjero las normas sobre obtención del certificado de estudios primarios y de escolaridad, dando satisfacción a una vieja aspiración de dotar de validez académica a las enseñanzas impartidas en esos centros. Unos años más tarde, en fin, el Congreso Sindical solicitaba al gobierno español «la creación en países europeos de colegios y escuelas para hijos de trabajadores españoles, a fin de que puedan ser educados y formados en el espíritu nacional» ${ }^{66}$. Sin embargo, una cosa era la teoría y otra la práctica. Por lo que respecta al caso francés, no parece que todas esas medidas y declaraciones públicas tuvieran una incidencia real durante la década de los años sesenta. La indolencia oficial sólo se vió alterada por la creciente implicación de la propia colonia española de emigrantes, que intensificó sus peticiones para la adopción de medidas que les permitieran conservar sus lazos culturales con España.

En 1960 había en Francia 6 maestros españoles (Béziers, Biarritz, Marsella -2- y París -2-) a cargo de escuelas de esta nacionalidad, un término sin duda demasiado optimista a juzgar por sus precarias condiciones. A lo largo de la década no variaron ni el número máximo de docentes ni la penuria en que se desenvolvió a menudo su labor. En esos centros se enseñaba fundamentalmente la lengua española, aderezada con algunos rudimentos de literatura, geografía e historia de España. No eran infrecuentes tampoco los pronunciamientos de los maestros en el sentido de inculcar a los alumnos «un ideal cristiano junto al orgullo de su ascendencia española». Aunque también es cierto que en varias de las escuelas la proporción entre asistentes españoles y franceses era casi equivalente.

En Béziers apenas se superaban los 50 alumnos en los años de mayor matrícula, manteniéndose las clases más por razones políticas de presencia en la zona que por su interés educativo. La escuela de Biarritz remprendió sus actividades tras la incorporación de un nuevo maestro. Su matrícula de alumnos se incrementó a unos 180 a mitad de la década. En Marsella los dos maestros desarrollaban una prolífica actividad. Además de las enseñanzas habituales, impartían otros cursos complementarios para alumnos de bachillerato o de correspondencia comercial, junto a cursos para estudiantes universitarios sobre Filología española o explicación de textos clásicos. La matrícula oscilaba entre los 300 y los 400 alumnos, e incluso las autoridades francesas reconocieron su trabajo al concederles las Palmes Académiques en 1963. Pero a mitad de la década ambos maestros llegaron a su edad de jubilación, ocasionando su relevo serios problemas ya que sus sucesores no estuvieron a su altura. En los años siguien-

66 «Orden del Ministerio de Educación Nacional», 1-I-1960. Boletín Oficial del Estado, 17-II1960. «Presidencia del Gobierno al Ministro de Asuntos Exteriores», 15-XII-1964. AMAE, R$10209 / 36$. 
tes se proyectó sustituir la escuela por un centro español de cultura, idea aplazada debido a la falta de recursos presupuestarios. En cuanto a las escuelas de París (una de niños y otra de niñas), la formación escolar se combinaba con clases de catecismo, especialmente entre las niñas que también recibían cursos complementarios de preparación para el bachillerato francés y de comercio. La asistencia a las clases, pese al incremento de la población española asentada en la región parisina, fue decreciendo lentamente a lo largo de esa década, pasando de cerca de 300 alumnos a poco mas de $200^{67}$.

Por otro lado, a principios de esa década se pusieron los pilares de un Instituto de Enseñanza Media en París. Inicialmente fue un cursillo realizado en la Biblioteca Española. En 1962 se convirtió en un Centro Experimental de Enseñanza Media, instalado en los locales de la Misión Española de la rue de la Pompe. Sus cursos los impartían profesores contratados, alcanzando una matrícula de 200 alumnos en su mayoría hijos de trabajadores españoles. En octubre de 1967 el centro se transformó legalmente en el Liceo Español de París, reuniendo en sus clases a unos 500 estudiantes. En aquel momento se desencadenó una huelga de profesores en demanda de condiciones de trabajo más estables y mejor remuneradas, que contó con un amplio respaldo de los estudiantes y sus padres. Solucionado el conflicto, el instituto comenzó su actividad en el nuevo edificio situado en Neuilly sur Seine ${ }^{68}$.

Ante una infraestructura que satisfacía en muy escasa medida sus necesidades educativas, los hijos de los emigrantes españoles, y una parte de los adultos, se incorporaron como venía siendo habitual al sistema escolar francés. El acceso a la lengua y la cultura del país de acogida facilitaba su integración, aumentaba sus posibilidades de mejorar su situación laboral y su promoción social. Aunque con limitaciones. A las complicaciones de adaptación a un sistema escolar distinto se añadían otros condicionantes que dificultaban su proceso educativo. En los medios emigrantes se fomentaba la orientación hacia la formación profesional, con lo que su asimilación a la ciudadanía francesa estaba ligada a su condición de trabajadores. El número de jóvenes españoles que accedían a los ciclos secundario y superior de enseñanza era bastante reducido. Además, como el resto de los extranjeros, sufrían discriminaciones en materia de concesión de becas, acceso a establecimientos públicos de segunda enseñanza y a otros tipos de estudios, o en la participación en diversos concursos ${ }^{69}$.

67 Los datos están extraidos de las memorias de los maestros localizadas en AMAE, R$10212 / 21,25,26$ y 33, y R-10213/2, 3, 12, 14 y 15.

68 «Enseñanza Media española en París», 30-IV-1962. AMAE, R-11052/20. «Reunión Patronato Centro Experimental de Enseñanza Media en París», 24-VI-1964; «Incidentes en el Centro Experimental de Enseñanza Media de París», 30-X-1967; «Informe del Director del Instituto Nacional de Enseñanza Media "Liceo Español". Curso 1967-68», 16-VII-1968. AGA-Ministerio de Educación Nacional, 36350.

69 HeRmeT, Guy: Los españoles..., pp. 82-91 y 116-144. 
Hasta finales de la década de los años sesenta no hubo variaciones significativas en esa situación. El impulso provino de los emigrantes, que deseaban asegurar a sus hijos una buena formación de base en el sistema educativo francés, sin renunciar por ello a una posible reinserción de los mismos en el marco educativo español. La expectativa del retorno permanecía presente, pero la prolongación de su estancia en Francia les llevó a tomar conciencia de las deficientes prestaciones que recibían de su país de origen. El nuevo aporte migratorio reactivó el movimiento asociativo español, ya preexistente.

En 1968 se constituyó, con el respaldo del gobierno español, la Federación de Asociaciones de Emigrantes Españoles en Francia, que incluyó entre sus objetivos la defensa y mejora de los vínculos culturales con España. El problema de la educación de sus hijos fue el principal elemento movilizador de otro sector de la colonia, aglutinado en torno a las misiones católicas. A partir del Concilio Vaticano II, buena parte de los religiosos destacados en Francia evolucionaron hacia posiciones de mayor compromiso social, asumiendo una postura crítica con la actuación del gobierno español respecto a los emigrantes. En las agrupaciones de las parroquías se debatía sobre los problemas de la escolaridad de los niños, el aprendizaje de la lengua española o las condiciones de preservación de la cultura y la identidad de su país natal. A finales de los años sesenta, esas reivindicaciones cristalizaron en un movimiento asociativo que exigía la organización de cursos de lengua española. Los sacerdotes apoyaron sus peticiones. En 1969 se organizaron clases complementarias de español en la misión de la rue de la Pompe, en París, al tiempo que pedían al gobierno español la dotación de profesores para ampliar sus enseñanzas. Hasta 1973 la escuela funcionó sin reconocimiento del gobierno francés, ni tampoco del español, que en esa fecha decidió incorporarlo a su estructura docente en Francia y darle carácter oficial. Al año siguiente surgía en París la primera Asociación de Padres de Familia de Emigrantes Españoles en Francia, germen de una Federación constituida en 1976. Con el tiempo las dos redes de asociaciones se fusionarían en la Federación de Asociaciones y Centros de Españoles Emigrantes en Francia. La demanda de recursos para la enseñanza de la lengua y la cultura españolas en Francia iba a permanecer como una de las reivindicaciones constantes de ese movimiento asociativo ${ }^{70}$.

Por otro lado, en febrero de 1969 vió la luz el Convenio de Cooperación Cultural, Científica y Técnica hispano-francés, que entró en vigor en noviembre de aquel año. Su articulado establecía, entre otras cuestiones, el compromiso mutuo de promover el conocimiento de la lengua y la cultura del otro país, favoreciendo su enseñanza en todos los niveles y en toda clase de establecimientos en que los programas oficiales establecidos por la ley previeran el estu-

70 Taboada Leonetti, Isabelle et Guillon, Michèle: Les inmigrés..., pp. 144-162; Babiano, José y FÉRNANDEZ ASPERILLA, Ana: El asociacionismo como estrategia cultural: los emigrantes españoles en Francia (1956/1974), Madrid, 1998, pp. 22 y ss.

Hispania, LXII/2, núm. 211 (2002) 521-560 
dio de una lengua viva extranjera. También se facilitaría la instalación y el funcionamientos de los centros de enseñanza de todos los niveles dependientes oficialmente de la otra parte o patrocinados por ella. Por último, el texto recogía que se arbitrarían los medios para el reconocimiento de los estudios, concursos y exámenes realizados en cada uno de los dos países, y se articularía un sistema de equivalencia parcial o total de los mismos ${ }^{71}$. Las crecientes demandas de la emigración y el nuevo marco del convenio cultural indujeron al gobierno español a abandonar progresivamente su anterior pasividad. Se creó el Consejo Escolar Primario, transformado en el Consejo Escolar para la Extensión Educativa de los Emigrantes en 1971. Con el concurso financiero del Instituto Español de Emigración, ese organismo debía ocuparse de poner en marcha unidades de lengua y cultura españolas en los principales países europeos receptores de emigrantes.

El gobierno francés, entretanto, flexibilizaba su tradicional política de asimilación escolar de las poblaciones extranjeras, lo que facilitó una mayor presencia docente española. En 1970 decidió la dotación de nuevas plazas de profesorado para la enseñanza del español y para la formación de profesores en esta lengua (tanto en Agrégation como en CAPES). A partir del curso preparatorio de onzième (11 años) existirían Secciones de español cuando hubiera un mínimo de 10 alumnos que optasen por esta lengua. Desde 1971 el gobierno español empezó a organizar clases complementarias de lengua y cultura. En aquellos años se contrataron unos noventa profesores para impartirlas. La enseñanza de los emigrantes parecía haber entrado finalmente en la agenda de la política exterior española ${ }^{72}$. La crisis económica de 1973 reforzó esa tendencia. La política migratoria francesa se hizo mucho más restrictiva durante la década de los años setenta, promoviéndose el retorno de esa población.

Las escuelas iban a dejar de ser exclusivamente centros de formación de ciudadanos franceses, algo que planteaba cada vez más conflictos derivados de la inadaptación cultural de los hijos de los emigrantes. Además, ahora había que considerar la posible vuelta de esos niños a sus países de origen, por lo que era preciso favorecer la enseñanza de la lengua y cultura de los mismos. Una circular del Ministerio de Educación francés, emitida en abril de 1975, modificó la anterior normativa establecida en 1939 sobre las clases de lenguas de origen para los hijos de emigrantes. Los docentes dispondrían en lo sucesivo de tres horas semanales para desarrollar sus enseñanzas, que se realizarían en centros franceses al finalizar el horario normal. Al igual que ocurriera con España,

\footnotetext{
71 «Convenio de Cooperación Cultural, Científica y Técnica entre la República Francesa y España», 7-II-1969. Boletín Oficial del Estado, 23-XII-1969.

72 «Memorandum de la reunión hispano-francesa celebrada en la Dirección General de Relaciones Culturales», 29-IV-1970»; «Esquema del Informe sobre los problemas más sobresalientes con que se enfrenta la economía y la sociedad española, desde la óptica del Ministerio de Asuntos Exteriores", 3-IV-1974. AMAE, R-32655 y R-12839. DiAZ-PLAJA, Guillermo: La condición emigrante.., pp. 303-304.
} 
se suscribieron acuerdos bilaterales con Portugal, Italia, Túnez, Marruecos, Yugoslavia, Turquía y Argelia, para que enviaran profesores que se encargasen de esa labor. Era un primer paso, pero esas clases complementarias aún no estaban incorporadas al sistema escolar francés ${ }^{73}$.

En cuanto a la red docente específicamente española se transformó de forma sustancial. Antes del final de la dictadura desaparecieron las escuelas de Béziers, Biarritz y Marsella. En París subsistía el colegio de la rue de la Pompe, al que se unían el Liceo Español y el colegio del Château de la Vallete en Pressigny-les-Pins (Loiret). Una estructura sumamente reducida, pero que ahora podía funcionar sin cortapisas. También en esa década de los años setenta el Instituto Español de Emigración puso en marcha un programa de becas para los hijos de los emigrantes. Entre 1970 y 1975 se otorgaron algo más de 90.000 becas, de las cuales casi las dos terceras partes eran para realizar estudios en España ${ }^{74}$.

Para entonces, ya había cesado la fase álgida de la emigración masiva hacia Francia. La nueva población había procurado asentarse con mayor comodidad en el país de acogida, una vez comprobado que el retorno no iba a producirse con la celeridad que habían previsto inicialmente. Habían recreado, como cualquier colonia emigrante, una red de sociabilidad que les permitía integrarse sin perder sus señas de identidad. En ese intervalo también habían tenido hijos que se escolarizaron en el sistema público francés, pues así tendrían más oportunidades de mejorar su posición social en el futuro. Además, tampoco tenían otras alternativas a su alcance.

Sin embargo, muchos de ellos no renunciaban a sus orígenes, ni se resignaban a permanecer para siempre en Francia. Por ello se movilizaban para mantener canales abiertos que facilitaran su regreso. Asegurar para sus descendientes una educación bilingue era dejar las puertas abiertas a una decisión que se tomaría llegado el momento. Otra parte importante de aquella población asumió que la mejora de su situación pasaba por aceptar la asimilación que ponía a su alcance la legislación francesa. Entre 1946 y 1970 optaron por naturalizarse franceses 135.858 españoles, a los que se sumaban otros 62.975 hijos de españoles que adquirieron la nacionalidad francesa por declaración. Las cifras eran considerables si tenemos en cuenta que la colonia española en 1975 se estimaba en 497.000 personas $^{75}$.

73 Parra LUNA, Francisco: La emigración española..., pp. 82 y ss.; SCHOR, Ralph: Histoire de limmigration..., p. 303; SODIGNÉ LOUSTAU, Jeanine: "L'émigration "économique" des années 60 . La "Seconde Génération": un groupe hétérogène. Interculturalisme et éducation", Exils et migrations ibériques au XX' siècle, 2 (1996), pp. 127-142.

74 Ministerio de Trabajo-Instituto Español de Emigración: Datos básicos de la emigración española 1975, Madrid, 1976, pp. 60-64.

75 TABOADA LEONETTI, Isabelle et GuILlon, Michèle: Les inmigrés..., pp. 94-105 y 133-139; RUBıo, Javier: La emigración española..., pp. 310 y 315. 
Hasta principios de la década de los años setenta el Estado español se había desentendido en buena medida de la atención educativa y cultural de los emigrantes en Francia. Quizás con la salvedad del período republicano, donde se abordó la cuestión con voluntad de resolverla, aunque con escasos medios para hacerlo. El número de escuelas o de maestros españoles en territorio francés era ridículo en comparación con el volumen de emigrantes allí asentados. Es cierto que los informes sobre el particular habían sido recurrentes, y que las gestiones diplomáticas se sucedieron a lo largo de aquellas décadas. Pero los resultados sobre el terreno eran meramente testimoniales. La actividad docente desplegada por el Estado español al otro lado de los Pirineos apenas llegaba a una ínfima porción de los españoles allí instalados. Claro está que los recursos destinados a tal efecto resultaban irrisorios. Desde España se reivindicaba el derecho de fomentar los vínculos culturales con sus emigrantes, pero no se iba más allá. Una actitud, en resumidas cuentas, más estética que práctica. Para los gobernantes españoles, esa cuestión estuvo lejos de representar una de las prioridades de la relación bilateral con Francia.

La situación empezó a modificarse cuando cambiaron las condiciones de actuación de los otros dos protagonistas en liza: el gobierno francés y los emigrantes. En lo que respecta al primero, desde la década de los años setenta se puso en tela de juicio la efectividad de la política tradicional de asimilación cultural de las poblaciones extranjeras que emigraban a su territorio. La imagen de la escuela republicana, formadora de ciudadanos franceses independientemente de su origen, se vió perturbada por un realidad menos idílica. El nuevo panorama venía marcado por un preocupante índice de fracaso escolar entre los hijos de los emigrantes, por la discriminación que afectaba a éstos en sus posibilidades de acceder a los niveles superiores de enseñanza, en fin por los conflictos que generaba un sistema que se mostraba incapaz de llevar a buen término aquella política de asimilación. En cuanto a los segundos, cada vez se mostraban menos resignados a aceptar la pasividad de las autoridades de su país de origen. Su estancia en Francia se dilataba, tenían hijos que crecían y había que educar, pero sin perder de vista la perspectiva de un posible retorno. Si ellos enviaban a su país de origen remesas de dinero que estaban contribuyendo al crecimiento nacional, era lógico que a cambio recibieran una mayor atención hacia sus necesidades. La toma de conciencia iba pareja al desarrollo de un movimiento asociativo que formulaba con creciente firmeza sus demandas.

La acción combinada de ambos factores, mayor flexibilidad francesa y mayor capacidad de presión de la emigración, indujo al gobierno español en el último tramo del régimen franquista a romper con las inercias anteriores e incrementar los medios dedicados a la enseñanza de los emigrantes. Pero hubo que esperar al restablecimiento de la democracia en España para que aquella nueva dinámica se plasmase en un cambio sustancial de escenario.

La llegada de la democracia a España favoreció, inicialmente, una mayor receptividad hacia las demandas educativas de los emigrantes. Existía mala 
conciencia por la dejadez anterior que habían sufrido, junto a un reconocimiento al esfuerzo que habían hecho los propios emigrantes por preservar su identidad cultural. Incluso, no hay que olvidarlo, los emigrantes que habían mantenido la nacionalidad española tenían derecho al voto en las elecciones políticas, lo que incrementaba su interés potencial para los nuevos dirigentes españoles. La consolidación del sistema democrático fue acompañada de un deseo de regular y mejorar la situación de la cultura española en el exterior. La acción educativa hacia los emigrantes en Francia se intensificó, se avanzó en un sistema de equivalencias de estudios entre ambos países, y se organizó una estructura docente más diversificada e integrada, parcialmente, en el programa escolar de los centros franceses.

Simultáneamente, la emigración fue perdiendo fuerza númerica con el paso de los años, al tiempo que España incrementaba su riqueza y dejó de ser un país de emigración para devenir un país de inmigración. Los planteamientos sobre la atención educativa a los emigrantes fueron cambiando, ya no se basaban en la idea del retorno sino en favorecer la integración y participación de esa población en la sociedad de acogida. La iniciativa correspondía pues a esos países, con los que se estaba dispuesto a colaborar para que los emigrantes no perdieran la relación con su tierra de origen. Además, la plena integración de España en Europa reforzó la tendencia a proyectar una imagen que resaltase su capacidad como potencia cultural, la enseñanza del español a estudiantes extranjeros adquirió mayor relieve que su mantenimiento entre los hijos de los emigrantes. En otros términos, la emigración ya empezaba a pertenecer al pasado. El análisis de esa fase reciente merece un tratamiento detallado, que permita completar la visión del proceso abordado en estas páginas. 